\title{
Liquid water absorption and scattering effects in DOAS retrievals over oceans
}

\author{
E. Peters, F. Wittrock, A. Richter, L. M. A. Alvarado, V. V. Rozanov, and J. P. Burrows \\ Institute of Environmental Physics (IUP), University of Bremen, Otto-Hahn-Allee 1, 28359 Bremen, Germany \\ Correspondence to: E. Peters (enno.peters@iup.physik.uni-bremen.de)
}

Received: 25 April 2014 - Published in Atmos. Meas. Tech. Discuss.: 21 May 2014

Revised: 13 October 2014 - Accepted: 30 October 2014 - Published: 5 December 2014

\begin{abstract}
Spectral effects of liquid water are present in absorption (differential optical absorption spectroscopy DOAS) measurements above the ocean and, if insufficiently removed, may interfere with trace gas absorptions, leading to wrong results. Currently available literature cross sections of liquid water absorption are provided in coarser resolution than DOAS applications require, and vibrational Raman scattering (VRS) is mostly not considered, or is compensated for using simulated pseudo cross sections from radiative transfer modeling.

During the ship-based TransBrom campaign across the western Pacific in October 2009, MAX-DOAS (Multi-AXis differential optical absorption spectroscopy) measurements of light penetrating very clear natural waters were performed, achieving average underwater light paths of up to $50 \mathrm{~m}$. From these measurements, the retrieval of a correction spectrum $\left(\mathrm{H}_{2} \mathrm{O}_{\text {corr }}\right)$ is presented, compensating simultaneously for insufficiencies in the liquid water absorption cross section and broad-banded VRS structures. Small-banded structures caused by VRS were found to be very efficiently compensated for by the intensity offset correction included in the DOAS fit. No interference between the $\mathrm{H}_{2} \mathrm{O}_{\text {corr }}$ spectrum and phytoplankton absorption was found.

In the MAX-DOAS tropospheric $\mathrm{NO}_{2}$ retrieval, this method was able to compensate entirely for all liquid water effects that decrease the fit quality, and performed better than using a liquid water cross section in combination with a simulated VRS spectrum. The decrease in the residual root mean square (rms) of the DOAS fit depends on the measurement's contamination with liquid water structures, and ranges from $\approx 30 \%$ for measurements slightly towards the water surface to several percent in small angles above the
\end{abstract}

horizon. Furthermore, the $\mathrm{H}_{2} \mathrm{O}_{\text {corr }}$ spectrum was found to prevent misfits of $\mathrm{NO}_{2}$ slant columns, especially for very low $\mathrm{NO}_{2}$ scenarios, and thus increases the reliability of the fit. In test fits on OMI satellite data, the $\mathrm{H}_{2} \mathrm{O}_{\text {corr }}$ spectrum was found selectively above ocean surfaces, where it decreases the rms by up to $\approx 11 \%$.

\section{Introduction}

In the atmosphere and ocean, liquid water interacts with solar radiation in the visible wavelength range in a variety of ways. Its absorption spectrum, which is called, in the following, the $\mathrm{H}_{2} \mathrm{O}_{\text {liq }}$ spectrum, results from vibrational transitions (overtone and combination bands), and is relatively smooth in shape (e.g., Pope and Fry, 1997). It causes the characteristic blue color of clear water. Suspended matter, socalled yellow substances or colored dissolved organic matter (CDOM), often dominates the water color, but this is not the focus of this study. In addition, inelastic scattering processes, both vibrational Raman and Brillouin scattering, by water molecules, result in a change in the photon energy, and thus change the spectrum of the incident light (Kattawar and $\mathrm{Xu}$, 1992; Xu and Kattawar, 1994). Inelastic scattering produces a filling-in of Fraunhofer lines, similar to the Ring effect in the atmosphere that results from rotational Raman scattering (Grainger and Ring, 1962).

This study is concerned with the well-known remote sensing technique of differential optical absorption spectroscopy (DOAS) (e.g., Platt, 1994; Burrows et al., 2011). The DOAS method has been used for many years in order to detect atmospheric trace gases, e.g., $\mathrm{NO}_{2}, \mathrm{O}_{3}, \mathrm{IO}, \mathrm{BrO}, \mathrm{HCHO}$, and 

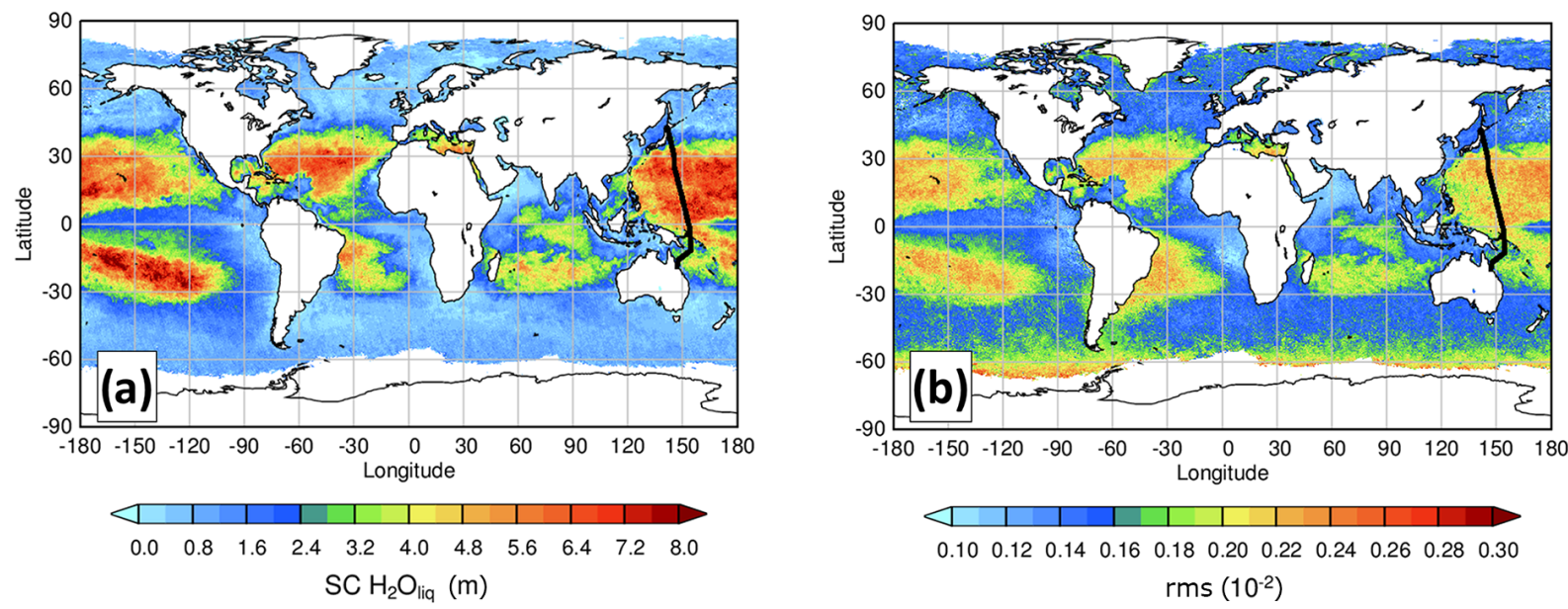

Figure 1. (a) Liquid water absorption (average length of the light path under water) as observed from $\mathrm{OMI}_{\text {for }} \mathrm{August}_{2007}$ in the $\mathrm{NO}_{2}$ DOAS fit (this is OMI-Fit2, as explained in Sect. 6 and Table 4). (b) rms of the same fit when excluding the liquid water absorption (i.e., rms from OMI-Fit1). Note that the rms in the south is enhanced because of sparse light in August. The cruise track during TransBrom is indicated in black.

CHOCHO, from space (e.g., Burrows et al., 1999; Martin et al., 2002; Richter et al., 2005; Wittrock et al., 2006; Schönhardt et al., 2008; De Smedt et al., 2008) as well as from the ground, ships and aircafts (e.g., Wittrock et al., 2004; Heckel et al., 2005; Peters et al., 2012; Pinardi et al., 2013; Großmann et al., 2013; Schönhardt et al., 2014).

In remote sensing observations (such as DOAS) of atmospheric trace gases in the visible wavelength range over water surfaces, both liquid water absorption and filling-in of Fraunhofer lines by liquid water are necessarily present, and may disturb the trace gas retrieval if insufficiently compensated for. Obvious examples are satellite nadir measurements such as from the GOME, SCIAMACHY, GOME-2, and OMI instruments (e.g., Burrows et al., 1995; Bovensmann et al., 1999; Callies et al., 2000; Levelt et al., 2006a, b). As an example, the liquid water absorption in the $\mathrm{NO}_{2}$ DOAS analysis of OMI measurements (see Sect. 6) is shown in Fig. 1a. It is important to mention that phytoplankton pigment absorption (which is not included in the DOAS analysis performed here) dominates the color of the water and, consequently, the pattern of liquid water absorption shown in Fig. 1a is very similar to the pattern of clear natural water having low chlorophyll concentration. However, if the liquid water absorption spectrum is not considered in the DOAS analysis, the rms of the fit reproduces the pattern of clear water as shown in Fig. 1b, while no enhanced rms is observed in regions where chlorophyll is present in higher amounts. Thus, the compensation of liquid water effects seems to limit the DOAS fit quality in the spectral region used here $(425-497 \mathrm{~nm})$, rather than chlorophyll absorption.

Several previous studies demonstrated the presence of liquid water effects in satellite observations. Most of them addressed the topic of vibrational Raman scattering (VRS). For example, Vasilkov et al. (2002) modeled ocean Raman scattering in the UV, and described a method to account for the effect on satellite measurements. Vountas et al. (2003) used for many years in order to detect studied the impact of VRS on trace gas retrievals from the GOME satellite instrument, and found that neglecting VRS can cause significant errors in the DOAS analysis, e.g., more than $30 \%$ for $\mathrm{BrO}$ slant columns over clear ocean scenarios. In the UV spectral range, the filling-in of Fraunhofer lines by VRS in the ocean is decreased by chlorophyll and dissolved organic matter (DOM) as they absorb UV radiation (also, the pure water absorption increases drastically with decreasing wavelength in the UV). This was used to retrieve the oceanic chlorophyll content by Joiner et al. (2004). Different phytoplankton groups have been derived from SCIAMACHY satellite measurements using their absorption characteristics in an adapted (phyto-)DOAS analysis (Vountas et al., 2007; Bracher et al., 2009). More recently, Rozanov et al. (2014) modeled the effect of inelastic Raman scattering in ocean water using the SCIATRAN radiative transfer model. With this, VRS was used in satellite data as a proxy for the abundance of light in the global ocean, which is an important parameter for modeling phytoplankton primary production (Dinter et al., 2014). However, spectral effects of liquid water are not only present in satellite nadir observations, but also in groundbased MAX-DOAS (Multi-AXis differential optical absorption spectroscopy) measurements towards the water surface, close to the horizon and even at small elevation angles above the horizon, as some photons observed under these viewing directions have traveled some distance within the water before being scattered into the line of sight. For example, Großmann et al. (2013) included a VRS spectrum to improve their MAX-DOAS fit of IO in the marine boundary layer over the remote ocean. 
In small DOAS fitting windows, the smooth liquid water absorption spectrum is often assumed to be sufficiently compensated for by the DOAS polynomial. This is most likely the reason for the variety of studies on VRS, while studies concerning the absorption structure are rare. However, for large fitting windows (> $40 \mathrm{~nm}$ in the visible wavelength range, depending on the actual fit settings and the order of the DOAS polynomial), liquid water absorption should be considered in the fit as demonstrated by Fig. 1b. This is supported by Richter et al. (2011), who found that including the $\mathrm{H}_{2} \mathrm{O}_{\text {liq }}$ spectrum in the GOME-2 DOAS fit for $\mathrm{NO}_{2}(425-$ $497 \mathrm{~nm}$ ) improves the fit quality. However, even in small fitting windows, $\mathrm{H}_{2} \mathrm{O}_{\text {liq }}$ can cause problems for the retrieval of weak absorptions if it is not compensated for. For example, for $\mathrm{CHOCHO}$, which is mostly retrieved in the range of $\approx 435-460 \mathrm{~nm}$, Lerot et al. (2010) developed a two-step approach, fixing the liquid water slant columns in the small glyoxal fitting window to results obtained in a larger fitting window where the smooth shape of the liquid water absorption spectrum can be retrieved more reliably.

Laboratory measurements of the pure liquid water absorption coefficient were performed, for example, by Pope and Fry (1997). Unfortunately, this absorption coefficient is given only in $2.5 \mathrm{~nm}$ steps, and the spectral resolution is even lower $(\approx 7 \mathrm{~nm}$ ). Even though the absorption structure is smooth, the coarse resolution blurs the exact position of shoulders in the $\mathrm{H}_{2} \mathrm{O}_{\text {liq }}$ spectrum. If the liquid water absorption is strong, this uncertainty can cause severe problems for the retrieval of trace gases using the DOAS method that requires a spectral resolution in the range of less than $1 \mathrm{~nm}$. In addition, the liquid water absorption spectra as measured by different groups differ clearly from each other in the $400-500 \mathrm{~nm}$ range (e.g., see Dickey et al., 2011), which is a result of the weak absorption strength in the visible wavelength range. As a consequence, very long light paths are needed to obtain reliable measurements. For the DOAS analysis, the 400$500 \mathrm{~nm}$ range is crucial, as many trace gases $\left(\mathrm{O}_{3}, \mathrm{NO}_{2}, \mathrm{CHO}-\right.$ $\mathrm{CHO}, \mathrm{IO})$ are retrieved here. Furthermore, laboratory measurements of liquid water absorption were made using pure water under standard conditions (i.e., for fixed temperature and pressure). In contrast, the water absorption that is present in field or satellite measurements is not pure, and does not apply to standard conditions.

In this study, we report on MAX-DOAS observations, pointing towards the water surface during the ship-borne TransBrom campaign in the western Pacific in 2009 where regions of remarkably clear water and low chlorophyll concentrations were encountered (see Fig. 1a). These measurements were designed in a way that minimizes atmospheric contributions to the resulting optical depth, while at the same time maximizing the liquid water influence. From these measurements, we retrieve a $\mathrm{H}_{2} \mathrm{O}_{\text {corr }}$ spectrum $(<1 \mathrm{~nm}$ resolution) compensating simultaneously for broad-banded VRS structures and uncertainties in currently available literature cross sections of liquid water absorption. The influence and

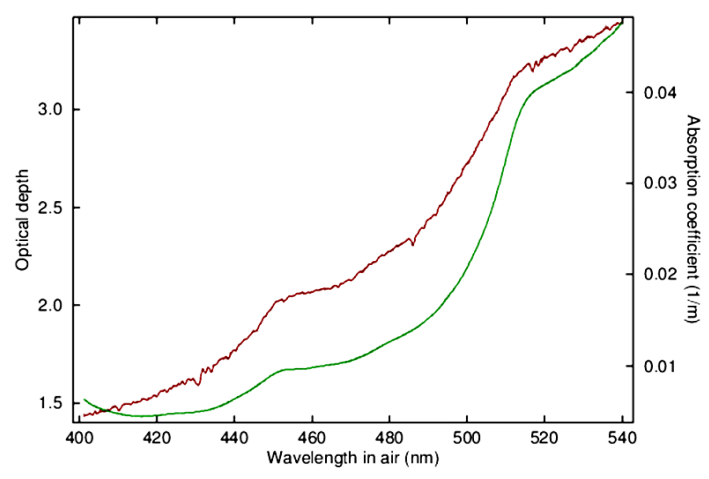

Figure 2. Green: liquid water absorption coefficient $\left(\mathrm{H}_{2} \mathrm{O}_{\text {liq }}\right.$ spectrum) from Pope and Fry (1997). Brown: logarithm of the ratio between an undisturbed and white cap spectrum in the water-pointing direction as described in Sect. 3.6, i.e., the optical depth of water (exemplarily for one measurement on 14 October 2009).

the potential improvement of the retrieved spectrum on the $\mathrm{NO}_{2}$ fit using atmospheric MAX-DOAS measurements close to and above the horizon taken during the same campaign are investigated. In addition, the $\mathrm{H}_{2} \mathrm{O}_{\text {corr }}$ spectrum was included in satellite DOAS fits, and the resulting fit factors (slant columns) were successfully found over the clear ocean.

The following Sect. 2 gives the theoretical background of liquid water spectral effects. Detailed information about the measurements performed as well as the DOAS method and the instrumentation is provided in Sect. 3. Section 4 reports on different attempts to retrieve empirical $\mathrm{H}_{2} \mathrm{O}_{\text {liq }}$ and VRS cross sections as well as the retrieval of the finally used $\mathrm{H}_{2} \mathrm{O}_{\text {corr }}$ spectrum. The influence of this spectrum on the $\mathrm{NO}_{2}$ fit in atmospheric MAX-DOAS measurements is investigated in Sect. 5. Finally, the presence of the $\mathrm{H}_{2} \mathrm{O}_{\text {corr }}$ spectral signature in OMI satellite data is demonstrated in Sect. 6.

\section{Spectral effects of liquid water}

The most important spectral feature of liquid water is its absorption $\mathrm{H}_{2} \mathrm{O}_{\text {liq }}$, which is different from the absorption spectrum of water vapor. Whereas the latter one is dominated by a large number of distinct vibrational-rotational absorption lines (caused by numerous rotational levels due to the $\mathrm{H}_{2} \mathrm{O}$ molecule's different moments of inertia for rotation around different spatial axes), in the liquid phase, rotations are suppressed as a result of intermolecular hydrogen bonding, and are limited to so-called librations (rocking, wagging and twisting). Also, in contrast to most other substances, the absorption of liquid water in the visible wavelength range is not based on electronic transitions. Instead, it is caused by overtones of the three fundamental vibrational modes: symmetric stretch $\left(v_{1}\right)$, asymmetric stretch $\left(v_{3}\right)$ and bending or scissors mode $\left(v_{2}\right)$. The result is a continuous absorption spectrum that is smooth in shape, with small values in the blue range and increasing values towards longer 
wavelengths. Thus, water absorbs more strongly in the red part of the spectrum that produces the blue color of the ocean. The absorption spectrum is plotted in Fig. 2 (green line). The dominant stretch modes of the $\mathrm{OH}$ bond $\left(v_{1}, v_{3}\right)$ occur at wave numbers of $\approx 3400 \mathrm{~cm}^{-1}(\approx 3 \mu \mathrm{m})$, and the bend or scissors mode $\left(v_{2}\right)$ appears at $\approx 1600 \mathrm{~cm}^{-1}(\approx 6 \mu \mathrm{m})$, which is in the infrared region. The absorption in the visible wavelength range is caused by harmonics, and linear combinations of these fundamental modes and strong transitions can be identified as shoulders in the absorption spectrum. For example, the shoulder at $\approx 450 \mathrm{~nm}$ corresponds to the seventh harmonic of the OH stretch (see Pope and Fry, 1997, and references therein). Hydrogen bonds developing between adjacent $\mathrm{H}_{2} \mathrm{O}$ molecules in the liquid phase decrease the vibrational energy levels of $\mathrm{OH}$ stretches, and thus cause a red shift in vibrational transition energies (Braun and Smirnov, 1993, and references therein). With increasing temperature, hydrogen bonding decreases in importance, as a larger fraction of bonds is broken. As a result, the red shift and therefore the exact position of absorption features (shoulders) is slightly temperature dependent (lower temperatures lead to larger red shifts).

In atmospheric remote sensing, the effect of rotational Raman scattering (RRS) on air molecules (predominantly $\mathrm{N}_{2}$ ) is well known. RRS is an inelastic scattering process that produces wavelength shifts in the spectrum. For example, Kattawar et al. (1981) found that the strongest Raman lines are typically $50 \mathrm{~cm}^{-1}$ from the frequency of the incident light. With this, a rough estimation yields a wavelength shift of $\approx 1 \mathrm{~nm}$ for an initial wavelength of $450 \mathrm{~nm}$. As this is comparable to the width of strong Fraunhofer lines (and is also in the range of typical DOAS instrumental resolution), more intensity is shifted from the wing of a Fraunhofer line to its core than from the core to the wing, simply because there is less intensity in the minimum that can be shifted. The result is a filling-in of Fraunhofer lines that was first observed by Grainger and Ring (1962) and that is known as the Ring effect.

Similarly, inelastic vibrational Raman scattering (VRS) can also occur in molecules that have vibrational modes, but the mechanism of filling-in of Fraunhofer lines is less efficient and, therefore, VRS in the atmosphere can be neglected. In contrast, in liquid water, the VRS effect on $\mathrm{H}_{2} \mathrm{O}$ molecules becomes important because of its high density. At the same time, no RRS can occur in liquid water, because no rotations are allowed. The final energy $E_{\text {fin }}$, or wavelength $\lambda_{\text {fin }}$, of an inelastic VRS scattered photon is

$$
\begin{aligned}
E_{\text {fin }} & =E_{\text {int }}-h \cdot c \cdot \widetilde{v} \\
& \leftrightarrow \frac{1}{\lambda_{\text {fin }}}=\frac{1}{\lambda_{\text {int }}}-\widetilde{v} .
\end{aligned}
$$

As the energy of the dominant $\mathrm{OH}$ stretch is in the range of $\widetilde{v} \approx 3400 \mathrm{~cm}^{-1}$ (see Fig. 3), for an initial wavelength $\lambda_{\text {int }}$ of $400 \mathrm{~nm}$, Eq. (1) yields a final wavelength of $\approx 460 \mathrm{~nm}$ (for

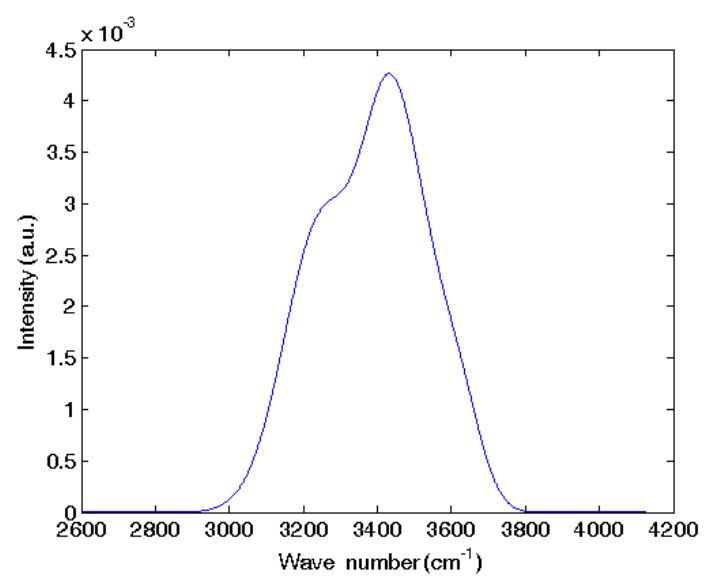

Figure 3. Illustration of the VRS band. The line shape was calculated according to Walrafen (1967) and Kattawar and Xu (1992).

the Stokes-Raman band); i.e., the VRS produces a wavelength shift of about $60 \mathrm{~nm}$ in the visible wavelength range. This maps larger structures of the initial sunlight spectrum to different positions, is much larger than the wavelength shift due to RRS on $\mathrm{N}_{2}$ molecules in the air, and is also much larger than the width of any Fraunhofer line. Consequently, the mechanism of filling in Fraunhofer lines from VRS is different from RRS, and results from the large line width of the VRS Raman band. First, the line width is large because of broadening effects in the liquid phase. In addition, the Raman band shape is a superposition of different Gauss curves associated with monomer (single $\mathrm{H}_{2} \mathrm{O}$ molecules) and polymer formation because of intermolecular hydrogen bonding. As this decreases the energy of the $\mathrm{OH}$ stretch (as mentioned above), the Raman band of polymers is centered at a different energy. For example, Walrafen (1967) and Kattawar and $\mathrm{Xu}$ (1992) described the Raman band as a superposition of four different Gauss curves (the resulting shape is plotted in Fig. 3$)$. As the overall line width $(\approx 8 \mathrm{~nm}$ in the visible wavelength range) is much greater than any Fraunhofer line, the level of both the wing and the core are raised by roughly the same amount; i.e., the core is less deep relative to the wing after the VRS (Xu and Kattawar, 1994). As the number of hydrogen bonds is temperature dependent, the shape of the Raman band is also temperature dependent. This has been used for remote sensing of the ocean temperature using LIDAR systems (e.g., Leonard et al., 1979).

To conclude, the resulting cross section of VRS is both small banded because of the filling-in of Fraunhofer lines as well as broad banded because of the large intensity shift that maps larger structures of the initial sunlight spectrum. An example of the cross section of VRS is given in Fig. 4 (Sect. 2.2). The prominent increase (step) around $460 \mathrm{~nm}$ results from the relatively sharp increase in intensity of the solar spectrum shortly before $400 \mathrm{~nm}$ (after the strong $\mathrm{K}$ and $\mathrm{H}$ Fraunhofer lines from $\mathrm{Ca}^{+}$). 


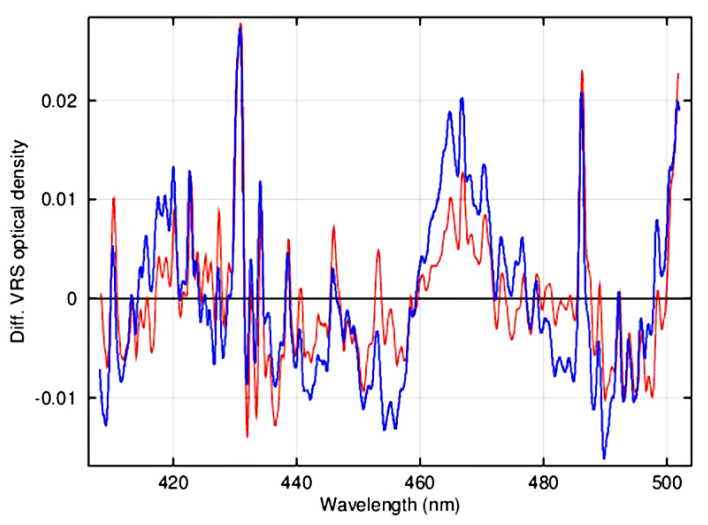

Figure 4. Blue: differential VRS cross section simulated using SCIATRAN (Sect. 2.2) for geometrical settings according to the ground-based measurements performed during TransBrom (V. Rozanov, personal communication, 2012). Red: differential VRS cross section retrieved from MAX-DOAS measurements (see Sect. 4).

Another inelastic scattering effect is the so-called Brillouin scattering that is caused by density fluctuations (phonons) in water (e.g., Hickman et al., 1991; Dickey et al., 2011). In principle, Brillouin scattering can also produce a filling-in of Fraunhofer structures, but the spectral shift is only several $10^{-3} \mathrm{~nm}$ in the visible wavelength range $(\mathrm{Xu}$ and Kattawar, 1994). This is much smaller than the shift of VRS or even RRS, and also smaller than the width of Fraunhofer lines that can be resolved with current (MAX-)DOAS instruments. Also, the Brillouin line width in the visible wavelength range $\left(\approx 10^{-4} \mathrm{~nm}\right)$ is much smaller than for VRS (Xu and Kattawar, 1994). To conclude, the Ring effect caused by Brillouin scattering can be neglected for current DOAS applications. More details can be found in Peters (2013), but they are not reproduced here, since the findings only confirm the intuitive assumption above.

\subsection{Bio-optical properties}

Bio-optical properties of ocean water are of high importance and can dominate the color of the ocean, as mentioned in Sect. 1. As a result, the pattern of liquid water absorption resembles the pattern of low chlorophyll concentration (compare Fig. 1 to chlorophyll maps, e.g., from Bracher et al., 2009).

Extensive studies have been performed in order to investigate and assess the apparent and inherent optical properties of ocean water. For example, Bricaud et al. (1998) analyzed total particulate absorption, aiming at providing an input parameter for modeling. Morel and Maritorena (2001) used measurements of spectral attenuation of downward irradiance and irradiance reflectance from ship cruises to develop a bio-optical model of the upper layer of the ocean, and found that semianalytical ocean color algorithms can be successfully applied to satellite data.

However, as mentioned in Sect. 1 and shown by Fig. 1a and $b$, the limiting factor for the $\mathrm{NO}_{2}$ DOAS fit seems to be interference with the $\mathrm{H}_{2} \mathrm{O}_{\text {liq }}$ absorption rather than phytoplankton pigment absorption. Furthermore, the cruise track during TransBrom indicated in Fig. 1a shows that the entire cruise was carried out in a region of very clear natural water (low chlorophyll content), and Fig. 2 demonstrates that the absorption of pure liquid water is by far the most dominant effect in the water-pointing measurements performed. Consequently, the focus of this study is on the compensation of clear liquid water absorption and scattering effects, while phytoplankton pigment absorption is neglected.

\subsection{SCIATRAN}

To compare simulated VRS spectra with the empirical spectra retrieved in this study, a pseudo cross section for the VRS effect has been simulated. Therefore, the radiance detected by the MAX-DOAS instrument (i.e., after transmitting the atmosphere and some water column) has been simulated twice: as usual, first, all relevant absorption and scattering effects in the atmosphere as well as in the ocean were included $\left(I_{+}\right)$. Then, the simulation was repeated, neglecting the effect of interest $\left(I_{-}\right)$. The optical density of the effect of interest (VRS) is then calculated by taking the logarithm of the ratio, i.e., $\ln \left(I_{+} / I_{-}\right)$.

The radiances within the atmosphere and ocean have been calculated using the SCIATRAN coupled ocean-atmosphere radiative transfer model (Rozanov et al., 2014; Blum et al., 2012). The extension of this version allows one to simulate different inelastic processes in the atmosphere and ocean. The details of the solution to the radiative transfer equation, including rotational Raman scattering in the atmosphere, can be found in Vountas et al. (1998) and Rozanov and Vountas (2014). The implementation of the inelastic processes such as the vibrational Raman scattering and chlorophyll fluorescence in the ocean radiative transfer model was performed following Haltrin and Kattawar (1993). For the simulation, clear water (low chlorophyll concentration of $0.1 \mathrm{mg} \mathrm{m}^{-3}$ ) was assumed, which is a realistic scenario for most of the campaign. The resulting spectrum is shown in Fig. 4 in blue. Note that, for a comparison between the simulated and empirical spectra, a fourth-order polynomial was subtracted from the simulated VRS spectrum, yielding a differential cross section.

\section{Measurements}

\subsection{The DOAS principle}

The DOAS method (e.g., Platt, 1994; Platt and Stutz, 2008) is based on the Lambert-Beer law that describes the attenuation of light of initial spectrum $I_{0}(\lambda)$ through absorbers $i$ 
(e.g., $\mathrm{O}_{3}, \mathrm{NO}_{2}$ ) of concentration $\rho_{i}(s)$ and absorption cross section $\sigma_{i}(\lambda)$ along the light path $s$ :

$$
\begin{aligned}
I(\lambda) & =I_{0}(\lambda) \cdot \exp \left(-\int_{0}^{L}\left[\sum_{i} \sigma_{i}(\lambda) \rho_{i}(s)\right.\right. \\
& +\sigma_{\text {Ray }}(\lambda) \rho_{\text {Ray }}(s)+\sigma_{\text {Mie }}(\lambda) \rho_{\mathrm{Mie}}(s)+\sigma_{\mathrm{RRS}}(\lambda) \\
& \left.\left.\rho_{\mathrm{RRS}}(s)+\sigma_{\mathrm{liq}}(\lambda) \rho_{\mathrm{liq}}(s)+\sigma_{\mathrm{VRS}}(\lambda) \rho_{\mathrm{VRS}}(s)\right] \mathrm{d} s\right) .
\end{aligned}
$$

In this equation, losses due to elastic scattering on molecules (Rayleigh) and aerosols (Mie) in the atmosphere are also explicitly considered, as well as inelastic rotational Raman scattering (RRS) on air molecules, leading to the atmospheric Ring effect. If a part of the light path is under water, VRS and liquid water absorption also occur ( $\sigma_{\text {liq }}$ and $\left.\sigma_{\mathrm{VRS}}\right)$, as well as chlorophyll absorption, which is neglected here, as mentioned before. For the atmospheric Ring effect due to RRS, a pseudo cross section $\sigma_{\text {RRS }}$ can be simulated using radiative transfer models like SCIATRAN and, as mentioned above, this is also possible for the VRS effect in liquid water (see Sect. 2.2).

If the cross sections $\sigma(\lambda)$ depend only on wavelength $\lambda$ and not on the light path $s$ (this is true for pure liquid water and, in most cases in first approximation, also for atmospheric absorbers), Eq. (2) yields the so-called DOAS equation

$\tau(\lambda)=-\sum_{i} \sigma_{i}^{\prime}(\lambda) \cdot \mathrm{SC}_{i}-\sum_{p} a_{p} \lambda^{p}+r(\lambda)$,

where $\tau(\lambda)=\ln \left(\frac{I(\lambda)}{I_{0}(\lambda)}\right)$ is the optical depth ( $I_{0}$ is usually a Sun spectrum for satellites, and a zenith spectrum for ground-based measurements), $r(\lambda)$ a residual spectrum and $\mathrm{SC}_{i}=\int \rho_{i}(s) \mathrm{d} s$ the so-called slant column, which is the concentration of absorber $i$ integrated along the light path. For simplicity, the atmospheric Ring effect (RRS) as well as liquid water absorption and VRS are included in the sum over absorbers in Eq. (3). In the absence of chlorophyll, the concentration of liquid water does not depend on the light path as $\rho_{\text {liq }} \approx$ const; i.e., in that case, $\sigma_{\text {liq }}(\lambda) \cdot \int \rho_{\text {liq }} \mathrm{d} s$ simplifies to $\sigma_{\text {liq }}(\lambda) \cdot \rho_{\text {liq }} \cdot s$. As a result, $\rho_{\text {liq }}$ can be included in $\sigma_{\text {liq }}(\lambda)$, yielding the absorption coefficient that is of dimension $m^{-1}$. The corresponding slant column is then of dimension $m$, and is simply the length of the average light path under water.

The basic idea of the DOAS method is to separate the observed optical depth into a high-frequency component and a low-frequency component. The low-frequency component describes (1) possible instrumental effects and (2) smooth changes in the spectrum caused by Rayleigh $\left(\lambda^{-4}\right.$ dependence) and Mie $\left(\lambda^{-\kappa}\right.$ dependence, $\left.\kappa \in[0,2]\right)$ scattering, i.e., $\sigma_{\text {Ray }}(\lambda)$ and $\sigma_{\text {Mie }}(\lambda)$. In addition, in satellite observations, the low-frequency component also compensates for the spectral surface reflectance. In Eq. (3), this low-frequency component is accounted for by a polynomial of small order (usually second to fourth order). The high-frequency component consists of the high-frequency parts $\sigma_{i}^{\prime}(\lambda)$ (differential cross sections) of absorber cross sections $\sigma_{i}(\lambda)$. The DOAS equation is then solved by means of a least-squares fit; i.e., the sum of squared residual points (chi square) is minimized. The square root of the chi square normalized by the number of spectral points is called the rms (root mean square), and is a measure of the fit quality. The fit results are the coefficients of the polynomial (which are of no interest here) and the slant columns $\mathrm{SC}_{i}$.

\subsection{Intensity offset correction (straylight correction)}

In the context of this work, the method of accounting for intensity offsets superposing the measured spectrum is important. These intensity offsets can be caused by different effects, e.g., changes in the detector's dark current. A prominent source of intensity offsets is straylight inside the spectrometer, which is predominantly light reflected on any surface and which finally reaches the CCD detector at a position that does not correspond to its wavelength. An additive amount of light $C$ (either real, i.e., straylight, or an instrumental artifact, i.e., dark current change) influences the resulting optical depth $\tau(\lambda)$ as follows:

$$
\begin{aligned}
\tau(\lambda) & =\ln \left(\frac{I(\lambda)+C}{I_{0}(\lambda)}\right)=\ln \left(\frac{I(\lambda)}{I_{0}(\lambda)}\right)+\ln \left(1+\frac{C}{I(\lambda)}\right) \\
& \approx \ln \left(\frac{I(\lambda)}{I_{0}(\lambda)}\right)+\frac{C}{I(\lambda)},
\end{aligned}
$$

where the Taylor expansion for $\ln (1+x)$ was stopped after the term of first order. Consequently, the intensity offset causes a term of optical depth that is proportional to $1 / I(\lambda)$.

In the DOAS analysis, this effect is routinely compensated for and called the intensity offset or straylight correction. For this purpose, after a first guess for $C$, the additive $C / I(\lambda)$ term is used as an additional differential cross section $\sigma_{\text {offset }}$ in the DOAS fit (i.e., a corresponding slant column is fitted). As a consequence of the $1 / I(\lambda)$ dependence, the differential cross section $\sigma_{\text {offset }}$ consists predominantly of Fraunhofer structures, and therefore has similarity to the Ring cross section of RRS in the atmosphere as well as to the narrow-band components of VRS in the ocean. This is intuitively clear: if a constant signal $C$ superposes a spectrum $I(\lambda)$, then the relative contribution is largest where the original spectrum has the lowest intensity, which is the case at the position of Fraunhofer lines.

The intensity offset correction (i.e., $\sigma_{\text {offset }}$ ) was found to compensate very efficiently for the small-band structures of VRS in water-leaving radiance. This has been already found in previous studies of Vountas et al. (2003). Note that higherorder intensity offset corrections (linear wavelength dependence, etc.) are sometimes also used, but for this study, a constant straylight correction turned out to be sufficient. 


\subsection{Instruments}

The focus of this study is on ground-based Multi-AXis (MAX)-DOAS measurements. In addition, OMI satellite data have been used in Sect. 6.

The IUP-Bremen MAX-DOAS instrument used here is a two-channel instrument consisting of two spectrometers for the UV and visible wavelength ranges, respectively, which are actively temperature stabilized at $35^{\circ} \mathrm{C}$. For this study, only measurements from the visible spectrometer are used, which is an Acton500 with a two-dimensional ROPER CCD camera with $100 \times 1340$ pixels covering a wavelength interval from 400 to $570 \mathrm{~nm}$ at a resolution of $0.8 \mathrm{~nm}$. The spectrometers are connected via a $20 \mathrm{~m}$ long Y-shaped optical fiber bundle consisting of $2 \times 38=76$ single fibers (and thus overcoming polarization effects) to a telescope unit that collects scattered sunlight. The telescope unit is mounted on a commercial ENEO VPT-501 pan-tilt head allowing pointing in any viewing direction. Light enters the telescope through a fused silica window, and is focused by a lens on the optical fiber bundle entrance. The telescope's field of view (FOV) is $\approx 1.2^{\circ}$. Inside the telescope housing, a video camera for scene documentation (taking snapshots every $5 \mathrm{~s}$ ) and a mercury-cadmium ( $\mathrm{HgCd}$ ) line lamp for calibration measurements are installed. All measurements and system operations are controlled by in-house software. The instrument demonstrated excellent performance during the CINDI intercomparison field campaign a few months before TransBrom (Roscoe et al., 2010; Piters et al., 2012; Pinardi et al., 2013), where it was selected as one of the reference instruments.

The Ozone Monitoring Instrument (OMI) is a nadirviewing imaging spectrometer on NASA's EOS Aura satellite launched on 15 July 2004 into a sun-synchronous, polar orbit at approximately $705 \mathrm{~km}$ in altitude. The local Equator crossing time is between 13:40 and 13:50. OMI measures direct and atmosphere-backscattered sunlight in the UV-VIS range from 270 to $500 \mathrm{~nm}$. Atmospheric observations are performed perpendicular to the flight direction in a $114^{\circ}$ field of view corresponding to a $2600 \mathrm{~km}$ wide spatial swath on the Earth's surface. Due to the large field of view, the ground-pixel size varies across the track from $24 \mathrm{~km}$ (nadir) to $128 \mathrm{~km}$ (edge of the swath). Global coverage is achieved in 1 day. Further information about the OMI satellite instrument can be found in Levelt et al. (2006a, b).

\subsection{The TransBrom field campaign}

TransBrom was a ship-borne field campaign across the western Pacific ocean. It was carried out onboard German research vessel Sonne, starting on 9 October 2009 in Tomakomai, Japan $\left(42^{\circ} 38^{\prime} \mathrm{N}, 141^{\circ} 37^{\prime} \mathrm{E}\right)$, and arriving on 24 October 2009 in Townsville, Australia $\left(19^{\circ} 15^{\prime} \mathrm{S}, 146^{\circ} 49^{\prime} \mathrm{E}\right)$. Due to a storm that hit Japan immediately before the campaign the instrument could only be set up at sea on 10 October 2009 , and consequently there is a lack of measurements in Japanese coastal waters. A campaign overview can be found in Quack (2010) and Krüger and Quack (2012). The campaign's focus was on measurements of short-living halogen (in particular bromine) compounds in the sea as well as in the air, and especially on the flux from sea to air, but this is not the topic of the present study. Furthermore, we have already reported on the MAX-DOAS contributions and measurements of atmospheric trace gases $\left(\mathrm{NO}_{2}, \mathrm{HCHO}, \mathrm{IO}\right)$ during TransBrom (Peters et al., 2012; Großmann et al., 2013).

The cruise track is plotted in Fig. 1a together with the liquid water absorption slant columns retrieved from the OMI satellite instrument for August 2007 (these slant columns result from the $\mathrm{OMI} \mathrm{NO}_{2}$ fits (OMI-Fit2), as explained in Sect. 6). As the liquid water absorption coefficient from Pope and Fry (1997), which is of dimension $m^{-1}$, was used in that fit ( $\rho_{\text {water }} \approx$ const, see Sect. 3.1 ), the resulting slant columns are of dimension $m$ and give the average length of the light paths that the ensemble of photons registered in the respective measurement have spent under water. Obviously, the TransBrom cruise was carried out almost entirely in a region of very clear water, where average underwater light paths of $\approx 7 \mathrm{~m}$ occur in measurements from the satellite. From the MAX-DOAS measurements being installed on RV Sonne and pointing directly into the water, even longer light paths (up to $50 \mathrm{~m}$ ) were achieved.

\subsection{MAX-DOAS setup and viewing geometry}

During the TransBrom campaign, the MAX-DOAS telescope unit was installed on the monkey deck above the bridge of RV Sonne, pointing portside. For measurements of atmospheric trace gases, vertical scans at elevation angles ranging from $-3^{\circ}$ (slightly towards the water surface) to $30^{\circ}$ above the horizon were performed in an azimuthal direction perpendicular to the ship (i.e., $-90^{\circ}$ relative to the ship's heading). These measurements are denoted as scanning directions in the following. Ground-based MAX-DOAS observations of tropospheric absorbers normally start at $0^{\circ}$ elevation angles. The scanning sequences performed here start at smaller elevation angles of $-3^{\circ}$ in order to obtain obvious liquid water contributions in atmospheric $\mathrm{NO}_{2}$ DOAS fits.

In addition, measurements pointing straight towards the water surface were taken at elevation angles of -45 and $-60^{\circ}$ with respect to the horizon, and in azimuthal directions of -45 and $-90^{\circ}$ relative to the ship's heading. These measurements are dominated by liquid water effects, and are denoted as water-pointing measurements in the following. The average length of the light path under water (up to $50 \mathrm{~m}$ in these directions) varies, depending on the viewing geometry (i.e., pointing direction and position of the Sun) as well as on the purity of water. 


\subsection{Clear water and white cap measurements}

Every water-pointing viewing direction was applied for an integration time of $40 \mathrm{~s}$. During this time, multiple spectra were recorded with very short exposure times of only $100 \mathrm{~ms}$ each. Due to the short exposure times, these single measurements can be regarded as spectral snapshots; i.e., the observed scene did not change significantly within a measurement, and they could be assigned to two groups: (1) clear water measurements (a clear and undisturbed view into the water body), and (2) white cap measurements. In the latter case, the observed scene was covered by white caps that occurred almost periodically (depending on the roughness of the sea) when waves slapped against the ship or collided with its bow wave. A color index (CI) was applied to characterize the dominant color in the observed scene, and to distinguish between these two cases. For this purpose, the average intensity in the 413-419 nm interval was divided by the average intensity in the interval of 548-554 nm. Finally, for each viewing angle, all $100 \mathrm{~ms}$ spectra with $\mathrm{CI}$ greater than 2 were assigned to the clear (blue) water spectra, and those with CI less than 1 were assigned to the white cap spectra.

In first approximation, the spectra of the white caps can be regarded as the reflection of the incoming light before penetrating the water (the water surface is thought to be covered by a white plane). Thus, the difference between white caps and undisturbed water measurements is in first order determined by the spectral effects of liquid water, while any atmospheric impact cancels out automatically. The optical depth of liquid water effects can be calculated in terms of the Lambert-Beer law ( $I=$ clear water, $I_{0}=$ white cap measurement), as $\ln \left(I / I_{0}\right)$, which is exemplarily plotted for one measurement from 14 October 2009 in Fig. 2 (brown line), in comparison to the liquid water absorption coefficient from Pope and Fry (1997). Note that the MAX-DOAS field measurements are observations of scattered light; i.e., the brown curve in Fig. 2 contains elastic and inelastic scattering effects. Nevertheless, the similarity to the water absorption is remarkable. In addition, the brown line reveals leftover structures from Fraunhofer lines that are caused by inelastic VRS. Thus, these measurements can be used to retrieve empirical cross sections of $\mathrm{H}_{2} \mathrm{O}_{\text {liq }}$ as well as VRS.

It is worth mentioning that the optical depth that is mainly liquid water in Fig. 2 is as large as $\approx 2.5$ at $497 \mathrm{~nm}$ (end wavelength of the $\mathrm{NO}_{2}$ fitting interval, as explained in the following sections). In contrast, the DOAS technique is usually applied for small absorptions of atmospheric trace gases. However, the assumption of small optical depth in DOAS applications is needed for two reasons: (1) the separation of light path calculation and spectral fit relies on the assumption that the light path length is not affected by the amount of absorber present, and (2) for molecules with strongly structured absorption spectra, the spectral signature changes if the absorption is large. Here, we are not interested in determining the exact amount of water molecules (determined by the underwater light path), and therefore we are not concerned with (1). As the absorption spectrum of liquid water has very little spectral structure, (2) is also not a problem in this case. Thus, the large optical depths are not problematic for use in the DOAS analysis in the context of this study.

\section{Retrieval of empirical (correction) spectra}

The original objective of retrieving empirical cross sections of liquid water absorption and VRS had only limited success, as discussed in Sects. 4.2 and 4.3. However, the obtained findings suggested the retrieval of correction spectra for (potentially non-perfect) literature cross sections (Sect. 4.4).

For all approaches discussed in this section, the $I$ and $I_{0}$ spectra (clear water, or white caps) were used in DOAS fits, and a polynomial was fitted to the optical depths $\ln \left(I / I_{0}\right)$ to account for instrumental and elastic scattering effects. No trace gases were included in the fits, as the difference between $I$ and $I_{0}$ is considered to be liquid water effects only. In addition, in Sects. 4.3 and 4.4, a liquid water absorption spectrum $\left(\mathrm{H}_{2} \mathrm{O}_{\text {liq }}\right)$ from the literature was used in order to retrieve a correction spectrum for it. This $\mathrm{H}_{2} \mathrm{O}_{\text {liq }}$ spectrum had to be adapted to our DOAS routine requirements as described in Sect. 4.1. To ensure that atmospheric conditions are as constant as possible, for each measurement $I$, the closestin-time reference measurement $I_{0}$ was always selected. As a cut-off criterion, only measurements $I$ were taken for which a reference spectrum $I_{0}$ exists within $\triangle$ SZA less than $2^{\circ}$ $(\mathrm{SZA}=$ solar zenith angle $)$. Also, only spectra recorded at SZA less than $85^{\circ}$ were used. After applying the color index selection and these restrictions, about 5000 measurements remained and could be analyzed. In addition, even stronger restrictions were tested: the individual $100 \mathrm{~ms}$ measurements for each intergration time were averaged according to their color index. Then, all spectra $I$ were rejected if no $I_{0}$ exists within a period of $1 \mathrm{~min}$. While this reduces the number of observations (predominantly because of the averaging), the results were always the same as in the first case.

\subsection{Preparation of the literature $\mathrm{H}_{2} \mathrm{O}_{\text {liq }}$ spectrum}

The liquid water absorption from Pope and Fry (1997) had to be prepared in order to include it as a cross section in our DOAS fitting routine (smoothing over three adjacent points and spline interpolation to the spectral sampling of our instrument). These changes return a $\mathrm{H}_{2} \mathrm{O}_{\text {liq }}$ spectrum that is slightly different from the original one. However, the changes between prepared and original cross sections are small and different in shape from the correction spectra of liquid water absorption retrieved in Sect. 4.4 (which is demonstrated there). Nevertheless, it should be noted that the correction spectra were calculated using the modified $\mathrm{H}_{2} \mathrm{O}_{\text {liq }}$ cross section, and therefore describe corrections with respect to it. 


\subsection{Simultaneous retrieval of VRS and $\mathrm{H}_{2} \mathrm{O}_{\text {liq }}$}

First, a retrieval of empirical cross sections of VRS and $\mathrm{H}_{2} \mathrm{O}_{\text {liq }}$ simultaneously from DOAS residuals using a principal component analysis (PCA) was attempted. In the respective DOAS fit, only a polynomial accounting for elastic scattering under water was included (i.e., no $\mathrm{H}_{2} \mathrm{O}_{\text {liq }}$ and no VRS). Thus, the differential spectra of both, VRS as well as $\mathrm{H}_{2} \mathrm{O}_{\text {liq }}$, remained in the residuals.

In general, the idea of a PCA is to find a coordinate system in which a data set (here, a set of DOAS residuals) can be expressed more efficiently than in the initial coordinates. This is achieved by retrieving orthogonal basis vectors that point in the direction of the largest variance in the data (thus, residuals corresponding to different strengths of liquid water effects are needed, which is the case for the measurements used here, as mentioned above). As a result, the first few basis vectors or principal components may already describe the variance in the whole data set sufficiently. In addition, the principal components might have the meaning of cross sections of absorbers or effects that were excluded in the DOAS fit (but this is not necessarily the case).

Various DOAS fits differing in the spectral range and order of polynomial were tested and, for each fit, the respective residuals were analyzed using a PCA. However, the PCA was unable to separate the effects of $\mathrm{H}_{2} \mathrm{O}_{\text {liq }}$ and VRS from each other. In particular, the retrieved $\mathrm{H}_{2} \mathrm{O}_{\text {liq }}$ spectrum (first principal component) that is only broad-banded always consisted of both broadband structures as well as small-band Fraunhofer structures that are caused by VRS. To conclude, $\mathrm{H}_{2} \mathrm{O}_{\text {liq }}$ and VRS are not orthogonal effects; i.e., the PCA retrieves components that produce variance in the DOAS residuals independently of each other (orthogonal), which is not the case for VRS and $\mathrm{H}_{2} \mathrm{O}_{\text {liq. }}$. Both effects can be expected to produce larger spectral structures if the light path under water increases. As a result, the conclusion here is that both effects depend very similarly on the length of the underwater light path. This has important implications, because it overcomes the need to determine both independently, VRS as well as $\mathrm{H}_{2} \mathrm{O}_{\text {liq }}$. Instead, one cross section, for example VRS, can be improved in a way that not only describes the VRS effect, but compensates at the same time for insufficiencies of $\mathrm{H}_{2} \mathrm{O}_{\text {liq }}$.

\subsection{Retrieval of VRS}

Aiming at the retrieval of an empirical differential VRS cross section that compensates at the same time for insufficiencies of $\mathrm{H}_{2} \mathrm{O}_{\text {liq }}$, the modified literature cross section of $\mathrm{H}_{2} \mathrm{O}_{\text {liq }}$ (see Sect. 4.1) was included in a DOAS fit. The fit was performed in a spectral range from 408 to $502 \mathrm{~nm}$ covering the $\mathrm{NO}_{2}$ fitting window discussed in Sect. 5. Apart from the literature $\mathrm{H}_{2} \mathrm{O}_{\text {liq }}$ spectrum, only a fourth-order polynomial accounting for instrumental effects and elastic scattering under water was applied. This DOAS fit was performed on all water-pointing measurements
( -45 and $-60^{\circ}$ elevation angle) throughout the whole campaign. Afterwards, all DOAS residuals were averaged. The result is plotted in Fig. 4 (red line), in comparison to the VRS cross section modeled by SCIATRAN (blue line) for groundbased geometry and prevailing conditions during TransBrom (Sect. 2.2).

The similarity between the empirical and modeled VRS spectra in Fig. 4 is obvious. Nevertheless, some differences are observed, predominantly in the broadband structures that are larger in the simulated spectrum - most notably the step around $460 \mathrm{~nm}$. This has two possible reasons: (1) the smoother shape of the broadband structures could be realistic and caused by the uncertainty of $\mathrm{H}_{2} \mathrm{O}_{\text {liq }}$ that is potentially compensated for by the empirical VRS spectrum. (2) As the DOAS method is a least-squares fit, the polynomial and the liquid water absorption are arranged in a way that reproduces the measured optical depth $\tau(\lambda)$ optimally. Thus, in the DOAS retrieval fit, the broadband structures of VRS are partly compensated for by the DOAS polynomial and the broad $\mathrm{H}_{2} \mathrm{O}_{\text {liq }}$ spectrum. While the first reason is speculative, the second reason is certainly true to some extent.

In addition, in the retrieval fit of the empirical VRS spectrum, no intensity offset correction was applied, since this compensates very efficiently for the small-band VRS structures (incompletely removed Fraunhofer lines) as explained in Sect. 3.2. As a result, no retrieval of VRS was possible when the straylight correction was included. This implies that the resulting VRS spectrum in Fig. 4 might also contain small-band structures that are not caused by VRS alone, but also by straylight (or changes in the detector's dark current signal) that might have been present in the spectrometer.

\subsection{The $\mathrm{H}_{2} \mathrm{O}_{\text {corr }}$ (correction) spectrum}

As mentioned above, the observation that the applied straylight correction compensates for small-band Fraunhofer structures from VRS is consistent with previous findings by Vountas et al. (2003). Thus, if $\mathrm{H}_{2} \mathrm{O}_{\text {liq }}$, a (constant) intensity offset correction $\left(\sigma_{\text {offset }}\right)$, and a polynomial are included in a DOAS retrieval fit, then only the broadband VRS structures plus uncertainties in liquid water absorption remain in the fit residuals.

In order to investigate this approach, several DOAS fits differing in the fit range and order of polynomial have been performed. The detailed settings are summarized in Table 1. The resulting residuals have been averaged for the whole campaign and for each parameter set, and are exemplarily shown in Fig. 5a. Obviously, average residuals corresponding to different DOAS fits reveal the same general structure, even if retrieved in another fitting window or corresponding to another DOAS polynomial; i.e., the observed residual pattern seems to be rather stable. For example, the step at $\approx 460 \mathrm{~nm}$ that is caused by VRS is clearly visible in all spectra. Small-band structures are suppressed to a large extent in the average residuals as a consequence of 
Table 1. Settings for the different $\mathrm{H}_{2} \mathrm{O}_{\text {corr }}$ retrieval fits.

\begin{tabular}{|c|c|c|}
\hline Parameter & $\mathrm{H}_{2} \mathrm{O}_{\text {corr }}$ retrieval fit & Remarks \\
\hline Elevation angle & $-45^{\circ},-60^{\circ}$ & And different azimuths \\
\hline SZA & $<85^{\circ}$ & \\
\hline Measurements $(I)$ & Clear water & $\begin{array}{l}100 \mathrm{~ms} \text { individual } \\
\text { as well as integrated }\end{array}$ \\
\hline Reference $\left(I_{0}\right)$ & Closest sea spray & $\Delta \mathrm{SZA} \leq 2^{\circ}, \Delta t \leq 1 \mathrm{~min}$ \\
\hline Fitting window & $\begin{array}{l}408-502 \mathrm{~nm}, \\
412-498 \mathrm{~nm}, \\
412-470 \mathrm{~nm}, \\
425-497 \mathrm{~nm}\end{array}$ & $\mathrm{NO}_{2}$ fitting window \\
\hline DOAS polynomial & Second, third, fourth order & Third corresponds to $\mathrm{NO}_{2}$ fit \\
\hline Straylight correction & Constant and linear & Linear only tested (no further improvement observed) \\
\hline Liquid water & Included & Pope and Fry (1997) \\
\hline VRS & Not included & \\
\hline
\end{tabular}
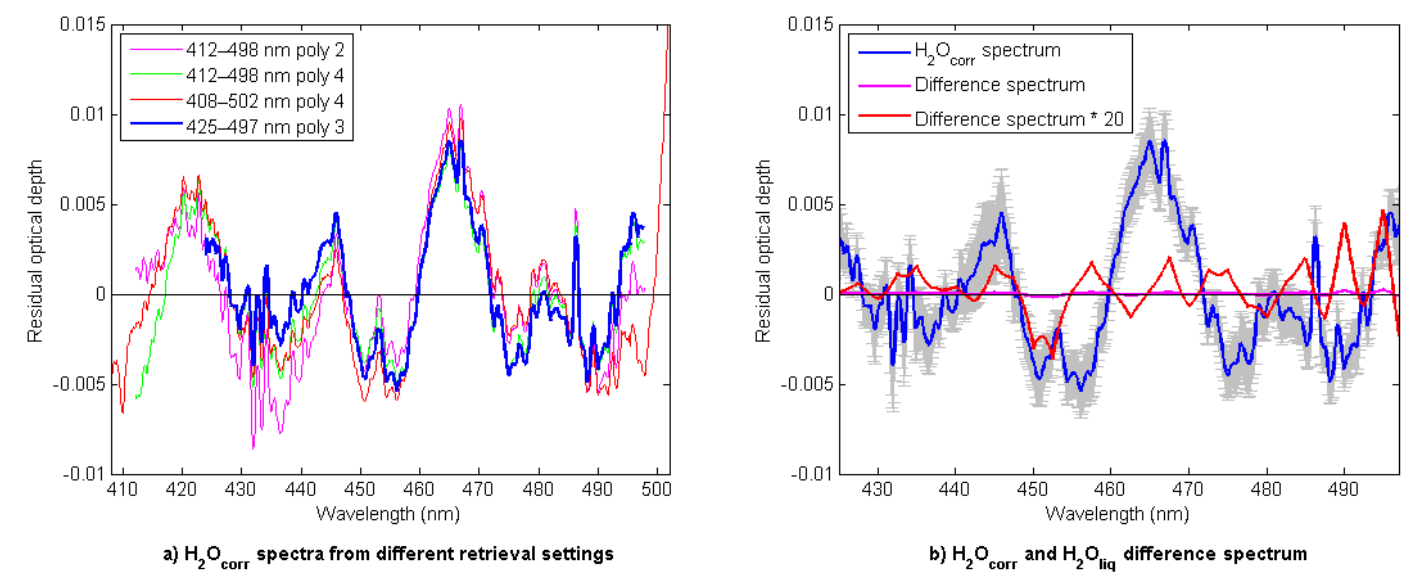

Figure 5. (a) Exemplary $\mathrm{H}_{2} \mathrm{O}_{\text {corr }}$ spectra obtained from different retrieval fit settings. Magenta: $412-498$ nm and second-order polynomial; green: $412-498 \mathrm{~nm}$ and fourth-order polynomial; red: 408-502 nm and fourth-order polynomial; blue: $425-497 \mathrm{~nm}$ and third-order polynomial ( $=\mathrm{NO}_{2}$ fit range and polynomial). (b) Blue: $\mathrm{H}_{2} \mathrm{O}_{\text {corr }}$ spectrum from $\mathrm{NO}_{2}$ fit settings (see a), with standard deviation from averaging compared to the difference spectrum between applied $\mathrm{H}_{2} \mathrm{O}_{\text {liq }}$ spectrum and (linear interpolated) spectrum from Pope and Fry (1997) in magenta (scaled by 20 in red).

the applied straylight correction (compare Figs. 5a to 4). The blue (slightly thicker) line in Fig. 5a results from a retrieval fit corresponding to the MAX-DOAS $\mathrm{NO}_{2}$ fit settings (425$497 \mathrm{~nm}$, third-order polynomial). This spectrum, in the following called the $\mathrm{H}_{2} \mathrm{O}_{\text {corr }}$ spectrum, is shown again in Fig. 5b together with the standard deviations resulting from the averaging. Obviously, the spectral structures of the $\mathrm{H}_{2} \mathrm{O}_{\text {corr }}$ spectrum are much larger than the uncertainties, demonstrating again that this residual pattern was stable and present in all averaged measurements.

As mentioned in Sect. 4.1, some processing was necessary for the liquid water absorption coefficient from Pope and Fry (1997) to allow its use in our DOAS routine. The difference between the modified cross section and the original one is shown in Fig. 5b (magenta line). Clearly, the resulting structures are much smaller than the $\mathrm{H}_{2} \mathrm{O}_{\text {corr }}$ spectrum. The magenta line was scaled by a factor of 20 (red line), so that the last peak is of the same size as the $\mathrm{H}_{2} \mathrm{O}_{\text {corr }}$ spectrum (blue line). The two curves show almost no agreement, and the correlation was calculated to $\approx 0.1$. In addition, it was verified that the $\mathrm{H}_{2} \mathrm{O}_{\text {corr }}$ spectrum is different from phytoplankton pigment absorption. For this, the $\mathrm{H}_{2} \mathrm{O}_{\text {corr }}$ spectrum was compared to the phytoplankton cross section from Prieur and Sathyendranat (1981) after subtracting a polynomial of the same order as the DOAS polynomial. The resulting correlation was 0.17 . Consequently, the retrieved $\mathrm{H}_{2} \mathrm{O}_{\text {corr }}$ spectrum can be assumed to result neither from the changes applied to the $\mathrm{H}_{2} \mathrm{O}_{\text {liq }}$ spectrum nor from phytoplankton absorption.

The advantage of the $\mathrm{H}_{2} \mathrm{O}_{\text {corr }}$ spectrum is that it is free of possible straylight contributions (and other intensity offsets) causing small-band structures. In DOAS fits above water surfaces, the $\mathrm{H}_{2} \mathrm{O}_{\text {corr }}$ spectrum can be used to compensate simultaneously for both, the uncertainties in the applied liquid water cross section (from the literature) and the broadband 
Table 2. Settings for different $\mathrm{NO}_{2}$ fits (with and without VRS, $\mathrm{H}_{2} \mathrm{O}_{\text {corr }}$ and $\mathrm{H}_{2} \mathrm{O}_{\text {liq }}$ ) performed to evaluate the effect of the retrieved $\mathrm{H}_{2} \mathrm{O}_{\text {corr }}$ spectrum. The fits were performed on measurements pointing at elevation angles between $-3^{\circ}$ (slightly towards the water surface) and $30^{\circ}$.

\begin{tabular}{|c|c|c|c|c|c|}
\hline Parameter & Fit1 & Fit2 & Fit3 & Fit4 & Remarks \\
\hline $\mathrm{H}_{2} \mathrm{O}_{\text {liq }}$ & No & Yes & Yes & Yes & $\begin{array}{l}\text { Prepared (Sect. 4.1) } \\
\text { Pope and Fry (1997) }\end{array}$ \\
\hline $\mathrm{H}_{2} \mathrm{O}_{\text {corr }}$ & No & No & Yes & No & Blue line in Fig. 5a and b \\
\hline VRS (SCIATRAN) & No & No & No & Yes & Blue line in Fig. 4 \\
\hline \multicolumn{6}{|l|}{ Common parameters } \\
\hline $\mathrm{O}_{3}$ & \multicolumn{4}{|c|}{$223 \mathrm{~K}$ (Bogumil et al., 2003) } & Same for all fits \\
\hline $\mathrm{NO}_{2}$ & \multicolumn{4}{|c|}{$295 \mathrm{~K}$ (Vandaele et al., 1996) } & Same for all fits \\
\hline $\mathrm{O}_{4}$ & \multicolumn{4}{|c|}{$\begin{array}{l}\text { Hermans et al., unpublished } \\
\text { (http://spectrolab.aeronomie.be/o2.htm) }\end{array}$} & Same for all fits \\
\hline Water vapor & \multicolumn{4}{|c|}{$\begin{array}{l}\text { Vandaele et al. (2005), Rothman et al. (2003), } \\
\text { using HITRAN 2009 }\end{array}$} & Same for all fits \\
\hline Ring & \multicolumn{4}{|c|}{ Following (Chance and Spurr, 1997) } & Same for all fits \\
\hline Polynomial & \multicolumn{4}{|c|}{ Third order } & Same for all fits \\
\hline Fit range & \multicolumn{4}{|c|}{$425-497 \mathrm{~nm}$} & Same for all fits \\
\hline Straylight correction & \multicolumn{4}{|c|}{ Constant } & Same for all fits \\
\hline Reference $\left(I_{0}\right)$ & \multicolumn{4}{|c|}{ Zenith direction, closest in time } & Same for all fits \\
\hline
\end{tabular}

structures of VRS, while the small-band VRS structures are largely compensated for by the DOAS straylight correction (which accounts at the same time for possible real straylight pollution in the measurements). Thus, using the $\mathrm{H}_{2} \mathrm{O}_{\text {corr }}$ spectrum overcomes the need to introduce a (simulated) VRS spectrum in the DOAS fit.

\section{Effects of the $\mathrm{H}_{2} \mathrm{O}_{\text {corr }}$ spectrum on the MAX-DOAS $\mathrm{NO}_{2}$ fit}

In this section, the effect of the retrieved $\mathrm{H}_{2} \mathrm{O}_{\text {corr }}$ spectrum on tropospheric $\mathrm{NO}_{2}$ fits in off-axis measurements close to the horizon is evaluated (elevation angles between -3 and $30^{\circ}$ and zenith measurements as reference $I_{0}$, see Sect. 3.5). These viewing directions are suitable for the detection of tropospheric absorbers, as they provide a long light path (i.e., enhanced sensitivity) close to the ground (e.g., Hönninger et al., 2004).

Four different MAX-DOAS fits of tropospheric $\mathrm{NO}_{2}$ were performed. Fit1 is mainly based on the MAX-DOAS $\mathrm{NO}_{2}$ fit settings used during the $\mathrm{NO}_{2}$ intercomparison campaign CINDI (Roscoe et al., 2010). It contains neither VRS nor liquid water absorption. Fit2 uses the same settings, but this time, the $\mathrm{H}_{2} \mathrm{O}_{\text {liq }}$ spectrum is included. In addition to $\mathrm{H}_{2} \mathrm{O}_{\text {liq }}$, Fit3 contains the $\mathrm{H}_{2} \mathrm{O}_{\text {corr }}$ spectrum retrieved in Sect. 4.4. Fit4 equals Fit3, but the $\mathrm{H}_{2} \mathrm{O}_{\text {corr }}$ spectrum is replaced by the SCIATRAN-simulated VRS spectrum shown in Fig. 4. To avoid contributions of stratospheric $\mathrm{NO}_{2}$ in the measurements, the closest-in-time zenith observation was always used as reference spectrum $I_{0}$. If no zenith spectrum was available within $\triangle \mathrm{SZA}=2^{\circ}$ around the measurement $I$, the respective measurement was rejected. The detailed fit settings are summarized in Table 2.

For measurements at the $-3^{\circ}$ elevation angle, the $\mathrm{H}_{2} \mathrm{O}_{\text {liq }}$ slant columns (or fit factors) of Fit2 are plotted in Fig. 6a in blue for the example of 14 October 2009, which was the day of best weather, viewing conditions and also clearest water during TransBrom. A distinct diurnal shape is found, which is mainly the result of the position of the Sun. Obviously, average underwater light paths of longer than $20 \mathrm{~m}$ occur around noon, although only slightly pointing towards the sea surface. In addition to the $\mathrm{H}_{2} \mathrm{O}_{\text {liq }}$ slant columns of Fit2, the (absolute values of) $\mathrm{H}_{2} \mathrm{O}_{\text {corr }}$ slant columns of Fit3 as well as the (absolute values of) VRS slant columns of Fit4 are plotted in Fig. 6a in red and green, respectively. The latter two lines have been scaled to the blue line in order to match into the figure according to

$a_{1}=\frac{\left(y_{1}, y_{2}\right)}{\left(y_{2}, y_{2}\right)} \quad a_{2}=\frac{\left(y_{1}, y_{3}\right)}{\left(y_{3}, y_{3}\right)}$

where (.) is the inner product, $a_{1}$ and $a_{2}$ are the scaling factors for the red and green lines, and $y_{1}, y_{2}$, and $y_{3}$ are the slant columns of $\mathrm{H}_{2} \mathrm{O}_{\text {liq }}, \mathrm{H}_{2} \mathrm{O}_{\text {corr }}$ and VRS, respectively.

Obviously, the diurnal shape of $\mathrm{H}_{2} \mathrm{O}_{\text {liq }}$ slant columns in Fig. 6a is reproduced by the $\mathrm{H}_{2} \mathrm{O}_{\text {corr }}$ slant columns of Fit3 as well as the VRS slant columns of Fit4, indicating that all spectra describe effects that scale very similarly with the length of the light path under water. This was already concluded in Sect. 4.2, and it is the prerequisite for using the $\mathrm{H}_{2} \mathrm{O}_{\text {corr }}$ spectrum to account simultaneously for both broadband structures of VRS as well as uncertainties in liquid water absorption.

In Fig. 6b, the corresponding rms of the fits shown in Fig. 6a is plotted in the same color coding. Apparently, the 


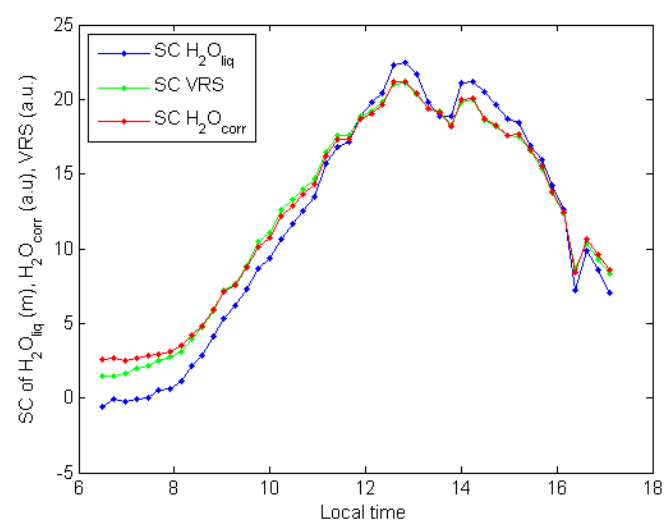

a) Slant columns of of $\mathrm{H}_{2} \mathrm{O}_{\text {liq }}, \mathrm{H}_{2} \mathrm{O}_{\text {corr }}$ and VRS (in different fits)

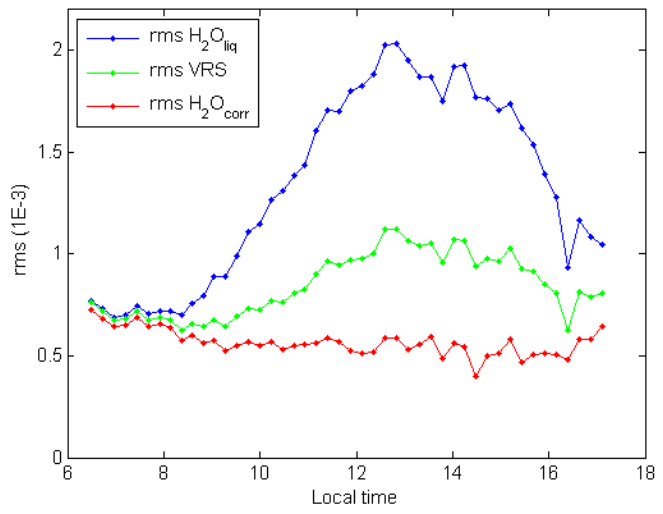

b) rms of corresponding fits

Figure 6. Fit results from measurements at a $-3^{\circ}$ elevation angle on 14 October 2009: (a) $\mathrm{H}_{2} \mathrm{O}_{\text {liq }}$ slant columns (SC) of Fit2 in blue, $\mathrm{H}_{2} \mathrm{O}_{\text {corr }}$ SC (absolute values) of Fit3 in red, and VRS SC (absolute values) of Fit4 in green (the red and green lines were scaled to the blue line in order to fit into the figure). (b) rms of the corresponding fits. For fit parameters, see Table 2.

rms of Fit2 is dominated by some water-related effects that are missing in the fit, as the rms reproduces the diurnal cycle of $\mathrm{H}_{2} \mathrm{O}_{\text {liq }}$ slant columns in Fig. 6a (note that the $\mathrm{H}_{2} \mathrm{O}_{\text {liq }}$ cross section from the literature is already included in Fit2). The rms of Fit1 ( no $\mathrm{H}_{2} \mathrm{O}_{\text {liq }}$ ) is outside the range of the figure, and therefore is not displayed, but it again reproduces the same shape. If the SCIATRAN-simulated VRS cross section is included in addition to $\mathrm{H}_{2} \mathrm{O}_{\text {liq }}$ (Fit4, green line), the rms is considerably smaller than in Fit2 (by a factor of up to 2 around noon). However, the same diurnal cycle is present in the rms, meaning that some water-related optical depth is still not accounted for. Finally, if the SCIATRAN VRS cross section is replaced by the $\mathrm{H}_{2} \mathrm{O}_{\text {corr }}$ spectrum (Fit3, red line), absolute values decrease again by a factor of up to 2 around noon and - even more importantly - the diurnal shape of liquid water absorption is no longer present. This indicates that in Fit3, all water-related effects are compensated for - at least those that scale with the light path under water and that are detectable with our instrument (this is the objective of this study). To conclude, the $\mathrm{H}_{2} \mathrm{O}_{\text {corr }}$ spectrum works as intended, and compensates (together with the straylight correction) for VRS as well as uncertainties in the applied liquid water absorption cross section from the literature.

Figure 7 shows the effect of the $\mathrm{H}_{2} \mathrm{O}_{\text {corr }}$ spectrum on the retrieved $\mathrm{NO}_{2}$ slant columns. The TransBrom campaign encountered marine-polluted regions of enhanced $\mathrm{NO}_{2}$ as well as very clean open ocean regions of very low $\mathrm{NO}_{2}(\approx 50 \mathrm{ppt}$, see Peters et al., 2012). Figure 7a and b are correlation plots between $\mathrm{NO}_{2}$ slant columns from Fit2 vs. Fit1 and Fit3 vs. Fit1, respectively. In these plots, all measurements in the vertical scanning directions from the whole campaign are plotted using color coding: measurements at elevation angles from -3 to $-1^{\circ}$, i.e., slightly towards the water surface, are displayed in red, 0 to $1^{\circ}$ in green, and 2 to $30^{\circ}$ in blue.
Figure $7 \mathrm{c}$ and $\mathrm{d}$ are correlation plots of the corresponding rms values of the different fits (same color coding).

Only measurements taken under appropriate wind directions were used for Fit1 to Fit4; i.e., measurements were rejected if the wind direction would blow the ship's plume into the line of sight. This is true for both, the off-axis measurements $I$ as well as the zenith reference measurements $I_{0}$, meaning that the reference $I_{0}$ should not contain more $\mathrm{NO}_{2}$ than the spectrum $I$. Thus, only positive $\mathrm{NO}_{2}$ slant columns should be retrieved from the DOAS fits, while negative slant columns indicate some problems in the fit (the fit would use the $\mathrm{NO}_{2}$ cross section to compensate for some other effects). In Fig. 7a, comparing the $\mathrm{NO}_{2}$ slant columns retrieved from the basic $\mathrm{NO}_{2}$ Fit1 and those from Fit2, two different cases have to be distinguished.

1. Positive $\mathrm{NO}_{2}$ slant columns from Fit1: in this case, all data points are located close to the $1: 1$ line, independent of the elevation angle. In particular, this means that (a) both fits find the same $\mathrm{NO}_{2}$ signal even if no liquid water absorption is included, but the measurements certainly contain liquid water structures, because they slightly point towards the water surface (red data points). Furthermore (b), if (almost) no liquid water structures are present in the measurements, but the $\mathrm{H}_{2} \mathrm{O}_{\text {liq }}$ cross section is included (Fit2), this does not affect the retrieved $\mathrm{NO}_{2}$ slant columns (blue data points are also on the $1: 1$ line); i.e., no mismatch of $\mathrm{NO}_{2}$ is introduced by including $\mathrm{H}_{2} \mathrm{O}_{\text {liq }}$ if this effect is not present in reality.

2. Negative $\mathrm{NO}_{2}$ slant columns from Fit1: this is physically not meaningful, and most likely is caused by the fit compensating liquid water structures with the $\mathrm{NO}_{2}$ cross section. For the -3 to $-1^{\circ}$ elevation angle, negative $\mathrm{NO}_{2}$ slant columns of up

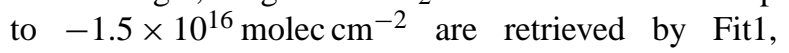



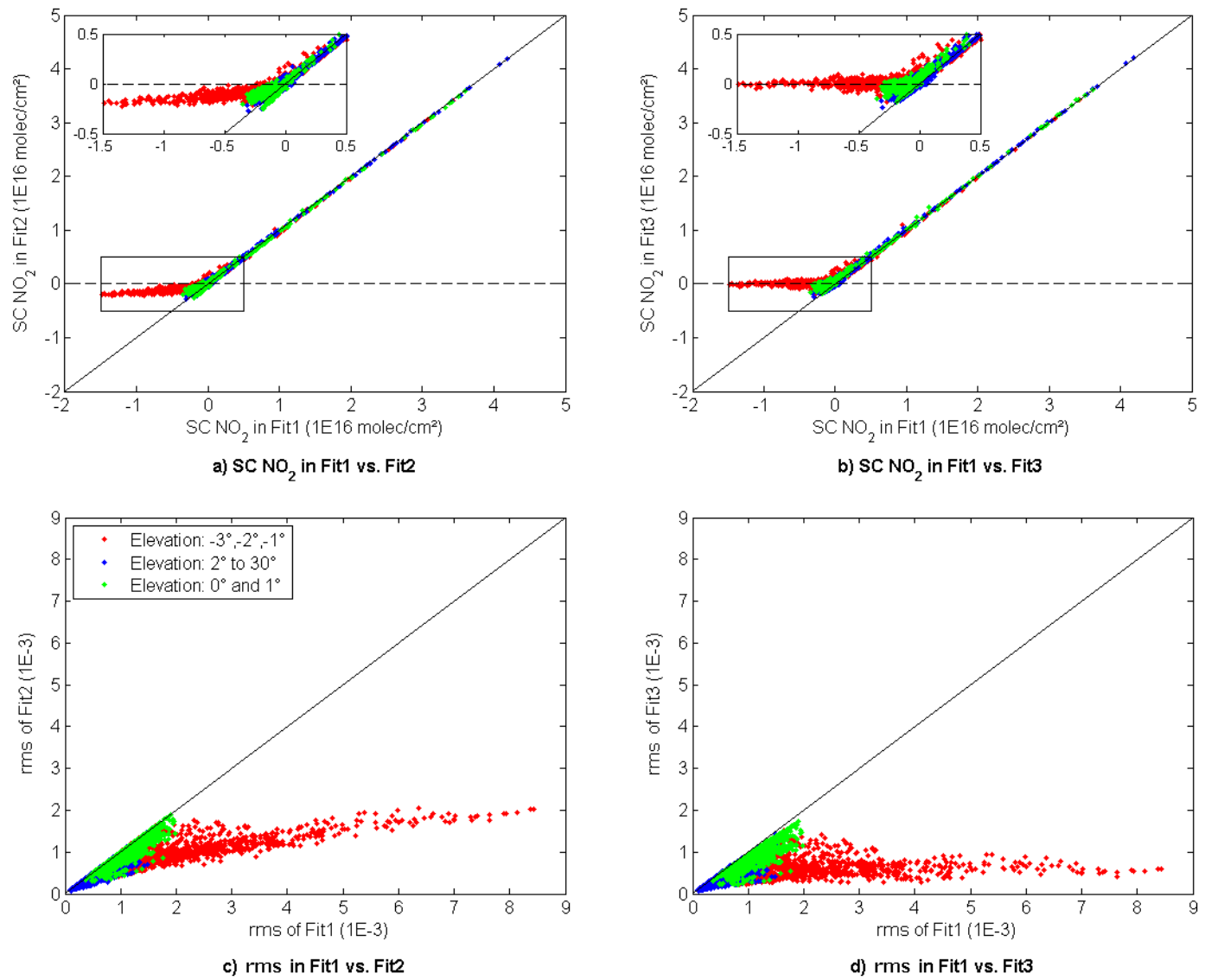

Figure 7. Influence of the $\mathrm{H}_{2} \mathrm{O}_{\text {corr }}$ spectrum on the $\mathrm{NO}_{2}$ slant column and rms in different DOAS fits. Color coded are different ranges of the elevation angle $\left(-3\right.$ to $-1^{\circ}$ in red, 0 to $1^{\circ}$ in green, 2 to $30^{\circ}$ in blue).

while measurements above the horizon reach only $\approx-4 \times 10^{15}$ molec $^{-2}$ (green and blue data points in the inset). Thus, the larger the measurement's contamination with liquid water structures is, the larger the introduced misfits in $\mathrm{NO}_{2}$ are (i.e., the more negative the $\mathrm{NO}_{2}$ slant columns are). If the $\mathrm{H}_{2} \mathrm{O}_{\text {liq }}$ cross section is included (Fit2), the $\mathrm{NO}_{2}$ is closer to zero, and slant columns are only retrieved in negative amounts up to $-2 \times 10^{15}$ molec $\mathrm{cm}^{-2}$, which is already in the range of the detection limit that was estimated at $2 \times 10^{-15}$ molec $\mathrm{cm}^{-2}$ in Peters et al. (2012). Thus, the problem is reduced but still present.

Using the $\mathrm{H}_{2} \mathrm{O}_{\text {corr }}$ spectrum overcomes this problem, as Fig. 7b demonstrates. In Fit3, containing not only $\mathrm{H}_{2} \mathrm{O}_{\text {liq }}$, but also the $\mathrm{H}_{2} \mathrm{O}_{\text {corr }}$ spectrum, formally negative $\mathrm{NO}_{2}$ slant columns (from Fit1 and Fit2) scatter around zero within the detection limit (DL) of $2 \times 10^{15} \mathrm{molec} \mathrm{cm}^{-2}$ (see the inset of Fig. 7b), which is more realistic and likely to be closer to the truth. This is not only the case for measurements towards the water (red data points), but also for measurements slightly above the horizon (green data points). Thus, when using zenith measurements as a reference (which is normally done for MAX-DOAS measurements), the resulting optical depth apparently contains water-related spectral structures at small elevation angles above the horizon (from photons that have been partly under water before being scattered into the instrument's line of sight). Consequently, $\mathrm{NO}_{2}$ can be misfit in these directions, but the $\mathrm{H}_{2} \mathrm{O}_{\text {corr }}$ spectrum in combination with $\mathrm{H}_{2} \mathrm{O}_{\text {liq }}$ overcomes this problem. As small elevation angles provide the longest light path through the boundary layer and therefore the highest sensitivity to tropospheric $\mathrm{NO}_{2}$, these are the most important MAX-DOAS directions. Thus, the achieved improvement is important for the reliability of MAX-DOAS measurements, especially of low $\mathrm{NO}_{2}$ concentrations above the ocean.

As in Fig. 7a, all positive $\mathrm{NO}_{2}$ slant columns in Fig. $7 \mathrm{~b}$ are close to the $1: 1$ line; i.e., if a $\mathrm{NO}_{2}$ signal is present in the measurements, the use of the $\mathrm{H}_{2} \mathrm{O}_{\text {corr }}$ spectrum does not affect the retrieved slant columns. To conclude, both $\mathrm{H}_{2} \mathrm{O}_{\text {liq }}$ as well as $\mathrm{H}_{2} \mathrm{O}_{\text {corr }}$ can be used in the MAX-DOAS $\mathrm{NO}_{2}$ fit presented here without unintended side effects, but increasing the reliability of retrieved $\mathrm{NO}_{2}$ slant columns over water.

Figure $7 \mathrm{c}$ and $\mathrm{d}$ demonstrate that the rms values of Fit2 and Fit3 are smaller than in Fit1. This is true for all elevation angles, but especially for those pointing slightly towards the 
water (red data points). Obviously, using the $\mathrm{H}_{2} \mathrm{O}_{\text {corr }}$ spectrum (Fit3) produces a much smaller rms than using liquid water absorption only (Fit2). Interestingly, the rms of Fit3 (Fig. 7d) is highest at the 0 and $1^{\circ}$ elevation angles (green data points). This is because the dominating effect on the rms is no longer errors introduced by liquid water effects, but misfits of water vapor in the atmosphere, which was present in large amounts in the humid air above the open ocean, and for which the largest slant columns occur at the 0 and $1^{\circ}$ elevation angles.

In order to quantify the improvement of the fit quality, the rms values of the different fits were compared to each other. First, for each single measurement, the difference between the rms in two fits was calculated and normalized by the rms of the first fit; e.g., (Fit1 - Fit2) / Fit1 gives the relative rms decrease of Fit2 with respect to Fit1. Afterwards, the obtained values of single measurements were averaged in certain ranges of elevation angles $\left(-3\right.$ to $-1^{\circ}, 0$ to $1^{\circ}, 2$ to $30^{\circ}$ ) for the whole campaign. The results are summarized in Table 3, supporting the findings above. The largest rms reduction is obtained by Fit 3 with respect to Fit 1 in the range of -3 to $-1^{\circ}$, which is on average $\approx 52.5 \%$, i.e., a factor of 2. For the same range of elevation angles, the comparison between Fit3 and Fit2 yields an rms reduction of up to $30 \%$ that is achieved by using the $\mathrm{H}_{2} \mathrm{O}_{\text {corr }}$ spectrum. In general, for all ranges of elevation angles, the rms reduction using the simulated VRS spectrum (Fit4) instead of the $\mathrm{H}_{2} \mathrm{O}_{\text {corr }}$ spectrum is smaller. Fit3 and Fit4 were compared directly, yielding on average a better performance of Fit 3 of $11.7 \%$ in -3 to $-1^{\circ}, 4.1 \%$ in 0 to $1^{\circ}$, and $3.2 \%$ in 2 to $30^{\circ}$. Obviously, the improvement using the $\mathrm{H}_{2} \mathrm{O}_{\text {corr }}$ spectrum instead of the simulated VRS spectrum is larger in viewing directions containing more liquid water structures, which is reasonable, since the $\mathrm{H}_{2} \mathrm{O}_{\text {corr }}$ spectrum compensates for insufficiencies in $\mathrm{H}_{2} \mathrm{O}_{\text {liq }}$.

Finally, it has to be mentioned that the numbers in Table 3 are averages of a specific campaign encountering specific conditions (e.g., if more measurements in regions of very clean water had been performed, the value of (Fit1 - Fit3) / Fit1 would have been even larger than it is here). Thus, the exact numbers do not necessarily apply to other measurements (under other conditions), but might represent typical values that can be expected for ship-based MAX-DOAS measurements over clear water.

\section{The $\mathrm{H}_{2} \mathrm{O}_{\text {corr }}$ spectrum in satellite data}

In addition to MAX-DOAS data, the retrieved $\mathrm{H}_{2} \mathrm{O}_{\text {corr }}$ spectrum was also tested on OMI satellite data (see Sect. 3.3). For this purpose, the four MAX-DOAS $\mathrm{NO}_{2}$ fits from Sect. 5 (425-497 nm, see Table 3) have been adapted to satellite requirements. In particular, for OMI-Fit4, a VRS cross section has been simulated with SCIATRAN using the satellite's nadir measurement geometry. The DOAS fits have been
Table 3. Normalized rms differences (in \%) of the performed fits averaged in specific ranges of elevation angles for the whole campaign.

\begin{tabular}{lcrr}
\hline & $-3,-2,-1^{\circ}$ & 0 to $1^{\circ}$ & 2 to $30^{\circ}$ \\
\hline (Fit1 - Fit2) / Fit1 & 37.6 & 10.6 & 10.9 \\
(Fit1 - Fit3) / Fit1 & 52.5 & 20.0 & 18.0 \\
(Fit1 - Fit4) / Fit1 & 48.4 & 16.8 & 15.4 \\
\hline (Fit2 - Fit3) / Fit2 & 29.7 & 11.1 & 8.5 \\
(Fit4 - Fit3) / Fit4 & 11.7 & 4.1 & 3.2 \\
\hline
\end{tabular}

performed on OMI data for August 2007, i.e., for a different period than the TransBrom campaign. The fit details are summarized in Table 4.

Figure 8a shows the resulting slant columns of the $\mathrm{H}_{2} \mathrm{O}_{\text {corr }}$ spectrum in OMI-Fit3 on a global scale. Obviously, locations at which the $\mathrm{H}_{2} \mathrm{O}_{\text {corr }}$ structure is found coincide with the pattern of clear natural water and low chlorophyll content (compare to Fig. 1a showing the $\mathrm{H}_{2} \mathrm{O}_{\text {liq }}$ slant columns from OMI-Fit2); i.e., the $\mathrm{H}_{2} \mathrm{O}_{\text {corr }}$ spectrum is successfully found in measurements of a different instrument on a different platform using data from a different period. This demonstrates again that the $\mathrm{H}_{2} \mathrm{O}_{\text {corr }}$ spectrum describes real liquid water residual effects, and is not due to any MAX-DOAS instrumental effect.

Interestingly, the (broad-banded) $\mathrm{H}_{2} \mathrm{O}_{\text {corr }}$ spectrum is not only found over the ocean, but also over some desert regions in northern Africa and the Arabian Peninsula (this is not visible in Fig. 8a, as continents are masked out). The reason is most likely interference with broadband sand structures that have already been found in GOME-2 data by Richter et al. (2011) over the desert. Nevertheless, this finding indicates that the $\mathrm{H}_{2} \mathrm{O}_{\text {corr }}$ spectrum should probably not be used in satellite observations over continents.

In Fig. 8b, the improvement of the rms of OMI-Fit3, i.e., using the $\mathrm{H}_{2} \mathrm{O}_{\text {corr }}$ spectrum, with respect to OMI-Fit4 (simulated VRS instead of $\mathrm{H}_{2} \mathrm{O}_{\text {corr }}$ ) is shown, and again reproduces the pattern of clear water regions. For this purpose, the differences between the rms of OMI-Fit4 and OMI-Fit3 have been calculated and normalized by the rms of OMI-Fit4 (similar to Sect. 5). In the same way, the changes in rms between the other fits were calculated. Averages of the calculated rms reduction over specific regions are summarized in Table 5. Region 1 (latitudes -20 to $45^{\circ} \mathrm{N}$, longitudes 140 to $160^{\circ} \mathrm{E}$ ) is a box around the TransBrom cruise track, while region2 (latitudes $0-30^{\circ} \mathrm{N}$, longitudes 130 to $180^{\circ} \mathrm{E}$ ) is a large oceanic region of clear water, i.e., where the amount of liquid water absorption is large. These regions are indicated in Fig. $8 \mathrm{~b}$ by dashed or solid rectangles. In addition, the global mean over all oceans is reported in Table 5 .

Including liquid water absorption (comparing OMI-Fit2 to OMI-Fit1) leads on average to $\approx 12 \%$ smaller rms globally over the ocean and $\approx 36 \%$ smaller rms in the specified 
Table 4. Settings for the DOAS test fits on OMI data. The OMI fits correspond to the MAX-DOAS NO 2 fits from Table 2.

\begin{tabular}{llllll}
\hline Parameter & OMI-Fit1 & OMI-Fit2 & OMI-Fit3 & OMI-Fit4 & Remarks \\
\hline $\mathrm{H}_{2} \mathrm{O}_{\text {liq }}$ & No & Yes & Yes & Yes & $\begin{array}{l}\text { Prepared (Sect. 4.1) } \\
\text { Pope and Fry (1997) } \\
\end{array}$ \\
$\mathrm{H}_{2} \mathrm{O}_{\text {corr }}$ & No & No & Yes & No & $\begin{array}{l}\text { Blue line in Fig. 5a and b } \\
\text { SCIATRAN simulation }\end{array}$ \\
VRS (SCIATRAN) & No & No & No & Yes & For satellite geometry \\
\hline Common parameters & & & & \\
\hline Trace gases & $\mathrm{O}_{3}(223 \mathrm{~K}), \mathrm{NO}_{2}(295 \mathrm{~K}), \mathrm{O}_{4}$, water vapor, Ring & Same for all fits \\
Polynomial & Third order & & & Same for all fits \\
Fit range & $425-497 \mathrm{~nm}$ & & Same for all fits \\
Straylight correction & Constant & & & Same for all fits \\
Reference $\left(I_{0}\right)$ & Solar spectrum & & & Same for all fits \\
Period & Aug 2007 & & & Same for all fits \\
\hline
\end{tabular}
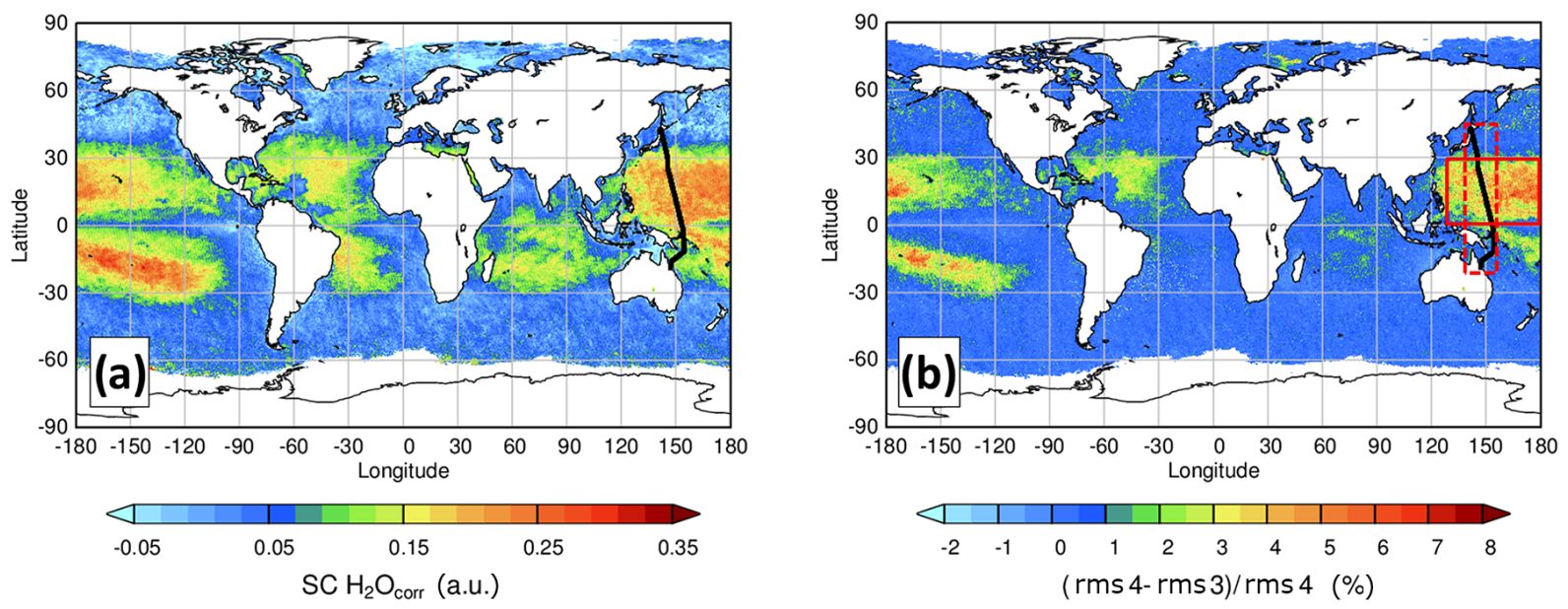

Figure 8. (a) $\mathrm{H}_{2} \mathrm{O}_{\text {corr }}$ slant columns of OMI-Fit3 (arbitrary units). (b) Normalized difference between the rms in OMI-Fit4 and OMI-Fit3, i.e., rms (Fit4 - Fit3) / Fit4, in percent. The cruise track is indicated in black. Displayed in red are the two regions from Table 5. Both plots are the monthly average of August 2007; for fit settings, see Table 4.

region2 of very clear water and low chlorophyll content. Also taking VRS into account, either by including a simulated VRS cross section (OMI-Fit4) or the $\mathrm{H}_{2} \mathrm{O}_{\text {corr }}$ spectrum (OMI-Fit3), reduces the rms with respect to OMI-Fit2 in region 2 by 7.9 and $10.8 \%$, respectively. In all regions, the $\mathrm{H}_{2} \mathrm{O}_{\text {corr }}$ spectrum performs better than the simulated VRS spectrum $(3.3 \%$ better in region 2 and still $0.7 \%$ better on a global scale). Again, this is most likely because the $\mathrm{H}_{2} \mathrm{O}_{\text {corr }}$ spectrum is compensating not only for broad-banded VRS structures, but also for residual $\mathrm{H}_{2} \mathrm{O}_{\text {liq }}$ structures, which the simulated VRS spectrum is not doing.

\section{Summary and conclusions}

Pure liquid water interacts with incident (solar) radiation in the visible wavelength range in terms of absorption $\left(\mathrm{H}_{2} \mathrm{O}_{\text {liq }}\right)$ and scattering (VRS, Brillouin), which has an impact on scattered light measured above the ocean (e.g., Fig. 1a). While Brillouin scattering can be neglected for current DOAS instrument resolutions, the effects of liquid water absorption and VRS need to be compensated for in DOAS retrievals. This is not fully achieved using currently available cross sections of $\mathrm{H}_{2} \mathrm{O}_{\text {liq }}$ and VRS (Figs. 6 and 1b). In contrast, phytoplankton pigment absorption seems not to increase the rms of the atmospheric $\mathrm{NO}_{2}$ DOAS fit in the visible spectral range, and is therefore neglected here.

In order to investigate pure liquid water effects, MAXDOAS measurements pointing directly to very clear natural waters (i.e., low chlorophyll concentrations) were taken during the TransBrom field campaign across the western Pacific in October 2009. Based on these measurements, it was not possible to retrieve independent empirical spectra of $\mathrm{H}_{2} \mathrm{O}_{\text {liq }}$ and VRS, because both effects depend in a similar way on the underwater light path (Fig. 6a). However, it turned out 
Table 5. Normalized rms differences (in \%) of the performed OMI fits (August 2007). On a global scale, the rms ratio (Fit4 - Fit3) / Fit4 is plotted in Fig. 8b. The values in this table are the averages of specific regions that are also displayed in Fig. $8 \mathrm{~b}$ (region $1=$ dashed red box, region $2=$ solid red box).

\begin{tabular}{lcrcc}
\hline & $($ Fit1 - Fit2) / Fit1 & (Fit2 - Fit3) / Fit2 & (Fit2 - Fit4) / Fit2 & (Fit4 - Fit3) / Fit4 \\
\hline Region1 & $28.2 \%$ & $7.5 \%$ & $5.6 \%$ & $2.0 \%$ \\
Region2 & $36.4 \%$ & $10.8 \%$ & $7.9 \%$ & $3.3 \%$ \\
Global mean (oceans) & $12.1 \%$ & $2.8 \%$ & $2.2 \%$ & $0.7 \%$ \\
\hline
\end{tabular}

to be possible to apply a simultaneous correction to both effects by using only one correction spectrum. In addition, the intensity offset or straylight correction, which is routinely included in the DOAS analysis as an additional pseudo absorber (Sect. 3.2), was found to compensate very efficiently for small-banded (incompletely removed Fraunhofer) structures produced by VRS. Thus, only broadband VRS structures need to be accounted for, which are broader than Fraunhofer lines, but still too narrowly banded to be compensated for by the DOAS polynomial.

From MAX-DOAS measurements, we retrieved an empirical residual correction spectrum $\left(\mathrm{H}_{2} \mathrm{O}_{\text {corr }}\right)$ that compensates for uncertainties in the literature $\mathrm{H}_{2} \mathrm{O}_{\text {liq }}$ spectrum as well as broadband structures of VRS. Using the $\mathrm{H}_{2} \mathrm{O}_{\text {corr }}$ spectrum together with $\mathrm{H}_{2} \mathrm{O}_{\text {liq }}$ in the MAX-DOAS $\mathrm{NO}_{2}$ fit compensates entirely for pure liquid water absorption as well as VRS (Fig. 6b). In unpolluted marine environments where unrealistic negative $\mathrm{NO}_{2}$ slant columns are retrieved in a standard evaluation, inclusion of the $\mathrm{H}_{2} \mathrm{O}_{\text {corr }}$ spectrum yields meaningful $\mathrm{NO}_{2}$ slant columns scattered around zero within the detection limit (Fig. 7). On the other hand, the $\mathrm{H}_{2} \mathrm{O}_{\text {corr }}$ spectrum was found to have no effect on $\mathrm{NO}_{2}$ slant columns in measurements containing no liquid water effects; i.e., no unwanted side effects arise. At the same time, the rms decreased by up to $29.7 \%$, depending on the elevation angle. For the most important elevation angles of MAX-DOAS measurements of tropospheric trace gases ( 0 and $1^{\circ}$ direction), the $\mathrm{H}_{2} \mathrm{O}_{\text {corr }}$ spectrum was found to decrease the rms by $11.1 \%$, and it performs $4.1 \%$ better than a simulated VRS spectrum (Table 3).

Apart from the improvement to MAX-DOAS measurements in a marine environment, the retrieved $\mathrm{H}_{2} \mathrm{O}_{\text {corr }}$ spectrum potentially also improves nadir measurements from airborne or space-borne platforms over clean water surfaces. In order to investigate this, the $\mathrm{H}_{2} \mathrm{O}_{\text {corr }}$ spectrum was tested on OMI satellite data over the ocean, and was successfully found, with a global distribution resembling the pattern of liquid water absorption (and low chlorophyll concentration), meaning that a potential improvement to satellite retrievals by our method is realistic (but not the topic of the present study). The average rms reduction of the $\mathrm{NO}_{2}$ DOAS fit due to the $\mathrm{H}_{2} \mathrm{O}_{\text {corr }}$ spectrum was found to be $10.8 \%$ in a region of very clear water (region2), where it performs on average
$3.3 \%$ better than when using a simulated VRS spectrum instead (Table 5).

It cannot be strictly ruled out that the $\mathrm{H}_{2} \mathrm{O}_{\text {corr }}$ spectrum is contaminated by any bio-optical property of water. However, this is unlikely, since (a) the $\mathrm{H}_{2} \mathrm{O}_{\text {corr }}$ spectrum was retrieved in a region of very clear water, (b) no similarity with chlorophyll absorption was found, and (c) when applied in satellite data, the locations at which $\mathrm{H}_{2} \mathrm{O}_{\text {corr }}$ is found resemble the pattern of low chlorophyll and large liquid water absorption, while no correlation with locations of larger chlorophyll concentrations is found.

As our $\mathrm{H}_{2} \mathrm{O}_{\text {corr }}$ spectrum replaces the VRS spectrum, no radiative transfer modeling of VRS is necessary, and the number of degrees of freedom of the DOAS fit stays constant (no additional cross section is included). The retrieved $\mathrm{H}_{2} \mathrm{O}_{\text {corr }}$ spectrum can be used in other DOAS applications that have similar settings (spectral range, order of polynomial) and use the same $\mathrm{H}_{2} \mathrm{O}_{\text {liq }}$ cross section as our retrieval fit.

Acknowledgements. We acknowledge the GEOMAR in Kiel, Germany, especially Birgit Quack and Kirstin Krüger for organizing the TransBrom campaign, as well as the crew of research vessel Sonne. Tilman Dinter from IUP Bremen provided VRS spectra simulated by SCIATRAN. The ship measurement work for this paper was partly funded by the BMBF through grant 03G0731A. The contribution at TransBrom from the University of Bremen was supported by the EU via the GEOMon integrated project (contract FP6-2005-Global-4-036677). The Bremen instrument was partly funded by the University of Bremen and the ENVIVALlife project (50EE0839). The authors would like to thank the editor, Folkert Boersma, as well as the two anonymous reviewers who helped to improve this publication. The service charges for this open-access publication have been partially covered by the Deutsche Forschungsgemeinschaft (DFG).

Edited by: F. Boersma

\section{References}

Blum, M., Rozanov, V. V., Burrows, J. P., and Bracher, A.: Coupled ocean-atmosphere radiative transfer model in the framework of software package SCIATRAN: Selected comparisons to model and satellite data, Adv. Space Res., 49, 1728-1742, 2012. 
Bogumil, K., Orphal, J., Homann, T., Voigt, S., Spietz, P., Fleischmann, O. C., Vogel, A., Hartmann, M., Kromminga, H., Bovensmann, H., Frerick, J., and Burrows, J. P.: Measurements of molecular absorption spectra with the SCIAMACHY preflight model: instrument characterization and reference data for atmospheric remote-sensing in the $230-2380 \mathrm{~nm}$ region, J. Photochem. Photobiol. A, 157, 167-184, 2003.

Bovensmann, H., Burrows, J. P., Buchwitz, M., Frerick, J., Noël, S., Rozanov, V. V., Chance, K. V., and Goede, A. P. H.: SCIAMACHY: mission objectives and measurement modes, J. Atmos. Sci., 56, 127-150, 1999.

Bracher, A., Vountas, M., Dinter, T., Burrows, J. P., Röttgers, R., and Peeken, I.: Quantitative observation of cyanobacteria and diatoms from space using PhytoDOAS on SCIAMACHY data, Biogeosciences, 6, 751-764, doi:10.5194/bg-6-751-2009, 2009.

Braun, C. L. and Smirnov, S. N.: Why is water blue?, J. Chem. Educ., 70, 612-614, 1993.

Bricaud, A., Morel, A., Babin, M., Allali, K., and Claustre, H.: Variations of light absorption by suspended particles with chlorophyll $\alpha$ concentration in oceanic (case 1) waters: Analysis and implications for bio-optical models, J. Geophys. Res., 103, 3103331044, 1998.

Burrows, J. P., Hölzle, E., Goede, A. P. H., Visser, H., and Fricke, W.: SCIAMACHY - Scanning Imaging Absorption Spectrometer for Atmospheric Chartography, Acta Astronaut., 35, 445-451, 1995.

Burrows, J. P., Weber, M., Buchwitz, M., Rozanov, V., LadstatterWeissenmayer, A., Richter, A., DeBeek, R., Hoogen, R., Bramstedt, K., Eichmann, K. U., and Eisinger, M.: The global ozone monitoring experiment (GOME): mission concept and first scientific results, J. Atmos. Sci., 56, 151-175, 1999.

Burrows, J. P., Platt, U., and Borrell, P.: The Remote Sensing of Tropospheric Composition from Space, Physics of Earth and Space Environments, Springer, Berlin, Heidelberg, 2011.

Callies, J., Corpaccioli, E., Eisinger, M., Hahne, A., and Lefebvre, A.: GOME-2 - Metop's Second-Generation Sensor for Operational Ozone Monitoring, ESA Bull.-Eur. Space, 102, 28-36, 2000

Chance, K. V. and Spurr, R. J. D.: Ring effect studies: Rayleigh scattering, including molecular parameters for rotational Raman scattering, and the Fraunhofer spectrum, Appl. Optics, 36, 52245230, 1997.

De Smedt, I., Müller, J.-F., Stavrakou, T., van der A, R., Eskes, H., and Van Roozendael, M.: Twelve years of global observations of formaldehyde in the troposphere using GOME and SCIAMACHY sensors, Atmos. Chem. Phys., 8, 4947-4963, doi:10.5194/acp-8-4947-2008, 2008.

Dickey, T. D., Kattawar, G. W., and Voss, K. J.: Shedding new light on light in the ocean, Phys. Today, 64, 44-49, 2011.

Dinter, T., Rozanov, V. V., Burrows, J. P., and Bracher, A.: Retrieving the availability of light in the ocean utilising spectral signatures of Vibrational Raman Scattering in hyper-spectral satellite measurements, Ocean Sci. Discuss., accepted, 2014.

Grainger, J. F. and Ring, J.: Anomalous Fraunhofer line profiles, Nature, 193, p. 762, doi:10.1038/193762a0, 1962.

Großmann, K., Frieß, U., Peters, E., Wittrock, F., Lampel, J., Yilmaz, S., Tschritter, J., Sommariva, R., von Glasow, R., Quack, B., Krüger, K., Pfeilsticker, K., and Platt, U.: Iodine monoxide in the Western Pacific marine boundary layer, Atmos. Chem. Phys. 13, 3363-3378, doi:10.5194/acp-13-3363-2013, 2013.

Haltrin, V., and Kattawar, G.: Self-consistent solution to the equation of radiative transfer with elastic and inelastic scattering in ocean optics: I Model, Appl. Optics, 32, 5356-5367, 1993.

Heckel, A., Richter, A., Tarsu, T., Wittrock, F., Hak, C., Pundt, I., Junkermann, W., and Burrows, J. P.: MAX-DOAS measurements of formaldehyde in the Po-Valley, Atmos. Chem. Phys., 5, 909918, doi:10.5194/acp-5-909-2005, 2005.

Hickman, G. D., Harding, J. M., Carnes, M., Pressman, A., Kattawar, G. W., and Fry, E. S.: Aircraft laser sensing of soundvelocity in water - Brillouin-scattering, Remote Sens. Environ., 36, 165-178, 1991.

Hönninger, G., von Friedeburg, C., and Platt, U.: Multi axis differential optical absorption spectroscopy (MAX-DOAS), Atmos. Chem. Phys., 4, 231-254, doi:10.5194/acp-4-231-2004, 2004.

Joiner, J., Vasilkov, A. P., Flittner, D. E., Gleason, J. F., and Bhartia, P. K.: Retrieval of cloud pressure and oceanic chlorophyll content using Raman scattering in GOME ultraviolet spectra, J. Geophys. Res.-Atmos., 109, D01109, doi:10.1029/2003jd003698, 2004.

Kattawar, G. W. and Xu, X.: Filling in of Fraunhofer lines in the ocean by Raman-scattering, Appl. Optics, 31, 6491-6500, 1992.

Kattawar, G. W., Young, A. T., and Humphreys, T. J.: Inelastic scattering in planetary atmospheres, I. The Ring effect, without aerosols, Astrophys. J., 243, 1049-1057, 1981.

Krüger, K. and Quack, B.: Introduction to special issue: the TransBrom Sonne expedition in the tropical West Pacific, Atmos. Chem. Phys., 13, 9439-9446, doi:10.5194/acp-13-9439-2013, 2013.

Leonard, D. A., Caputo, B., and Hoge, F. E.: Remote-sensing of subsurface water temperature by Raman-scattering, Appl. Optics, 18, 1732-1745, 1979.

Lerot, C., Stavrakou, T., De Smedt, I., Müller, J.-F., and Van Roozendael, M.: Glyoxal vertical columns from GOME-2 backscattered light measurements and comparisons with a global model, Atmos. Chem. Phys., 10, 12059-12072, doi:10.5194/acp10-12059-2010, 2010.

Levelt, P. F., Hilsenrath, E., Leppelmeier, G. W., van den Oord, G. H. J., Bhartia, P. K., Tamminen, J., de Haan, J. F., and Veefkind, J. P.: Science objectives of the Ozone Monitoring Instrument, IEEE T. Geosci. Remote, 44, 1199-1208, 2006a.

Levelt, P. F., Van den Oord, G. H. J., Dobber, M. R., Malkki, A., Visser, H., de Vries, J., Stammes, P., Lundell, J. O. V., and Saari, H.: The Ozone Monitoring Instrument, IEEE T. Geosci. Remote, 44, 1093-1101, 2006b.

Martin, R. V., Chance, K., Jacob, D. J., Kurosu, T. P., Spurr, R. J. D., Bucsela, E., Gleason, J. F., Palmer, P. I., Bey, I., Fiore, A. M., Li, Q. B., Yantosca, R. M., and Koelemeijer, R. B. A.: An improved retrieval of tropospheric nitrogen dioxide from GOME, J. Geophys. Res.-Atmos., 107, 4437, doi:10.1029/2001jd001027, 2002.

Morel, A., and Maritorena, S.: Bio-optical properties of oceanic waters: A reappraisal, J. Geophys. Re., 106, 7163-7180, 2001.

Peters, E.: Improved MAX-DOAS Measurements and Retrievals Focused on the Marine Boundary Layer, Ph.D. thesis, University of Bremen, available at: http://elib.suub.uni-bremen.de/ peid=D00103447 (last access: 20 May 2014), 2013. 
Peters, E., Wittrock, F., Großmann, K., Frieß, U., Richter, A., and Burrows, J. P.: Formaldehyde and nitrogen dioxide over the remote western Pacific Ocean: SCIAMACHY and GOME-2 validation using ship-based MAX-DOAS observations, Atmos. Chem. Phys., 12, 11179-11197, doi:10.5194/acp-12-111792012, 2012.

Pinardi, G., Van Roozendael, M., Abuhassan, N., Adams, C., Cede, A., Clémer, K., Fayt, C., Frieß, U., Gil, M., Herman, J., Hermans, C., Hendrick, F., Irie, H., Merlaud, A., Navarro Comas, M., Peters, E., Piters, A. J. M., Puentedura, O., Richter, A., Schönhardt, A., Shaiganfar, R., Spinei, E., Strong, K., Takashima, H., Vrekoussis, M., Wagner, T., Wittrock, F., and Yilmaz, S.: MAXDOAS formaldehyde slant column measurements during CINDI: intercomparison and analysis improvement, Atmos. Meas. Tech., 6, 167-185, doi:10.5194/amt-6-167-2013, 2013.

Piters, A. J. M., Boersma, K. F., Kroon, M., Hains, J. C., Van Roozendael, M., Wittrock, F., Abuhassan, N., Adams, C., Akrami, M., Allaart, M. A. F., Apituley, A., Beirle, S., Bergwerff, J. B., Berkhout, A. J. C., Brunner, D., Cede, A., Chong, J., Clémer, K., Fayt, C., Frieß, U., Gast, L. F. L., Gil-Ojeda, M., Goutail, F., Graves, R., Griesfeller, A., Großmann, K., Hemerijckx, G., Hendrick, F., Henzing, B., Herman, J., Hermans, C., Hoexum, M., van der Hoff, G. R., Irie, H., Johnston, P. V., Kanaya, Y., Kim, Y. J., Klein Baltink, H., Kreher, K., de Leeuw, G., Leigh, R., Merlaud, A., Moerman, M. M., Monks, P. S., Mount, G. H., Navarro-Comas, M., Oetjen, H., Pazmino, A., Perez-Camacho, M., Peters, E., du Piesanie, A., Pinardi, G., Puentedura, O., Richter, A., Roscoe, H. K., Schönhardt, A., Schwarzenbach, B., Shaiganfar, R., Sluis, W., Spinei, E., Stolk, A. P., Strong, K., Swart, D. P. J., Takashima, H., Vlemmix, T., Vrekoussis, M., Wagner, T., Whyte, C., Wilson, K. M., Yela, M., Yilmaz, S., Zieger, P., and Zhou, Y.: The Cabauw Intercomparison campaign for Nitrogen Dioxide measuring Instruments (CINDI): design, execution, and early results, Atmos. Meas. Tech., 5, 457-485, doi:10.5194/amt-5-457-2012, 2012.

Platt, U.: Differential optical absorption spectroscopy (DOAS), Chem. Anal. Ser., 127, 27-83, 1994.

Platt, U. and Stutz, J.: Differential Optical Absorption Spectroscopy: Principles and Applications, Physics of Earth and Space Environments, Springer, Berlin, Heidelberg, 2008.

Pope, R. M. and Fry, E. S.: Absorption spectrum (380-700 nm) of pure water, II. Integrating cavity measurements, Appl. Optics, 36, 8710-8723, 1997.

Prieur, L. and Sathyendranat, S.: An optical classification of coastal and oceanic waters based on the specific spectral absorption curves of phytoplankton pigments, dissolved organic matter, and other particulate materials, Limnol. Oceanogr., 26, 671-689, 1981.

Quack, B.: Cruise Report TransBrom SONNE, Tech. rep., IFM Geomar, 2010.

Richter, A., Burrows, J. P., Nüß, H., Granier, C., and Niemeier, U.: Increase in tropospheric nitrogen dioxide over China observed from space, Nature, 437, 129-132, 2005.

Richter, A., Begoin, M., Hilboll, A., and Burrows, J. P.: An improved $\mathrm{NO}_{2}$ retrieval for the GOME-2 satellite instrument, Atmos. Meas. Tech., 4, 1147-1159, doi:10.5194/amt-4-1147-2011, 2011.

Roscoe, H. K., Van Roozendael, M., Fayt, C., du Piesanie, A., Abuhassan, N., Adams, C., Akrami, M., Cede, A., Chong, J.,
Clémer, K., Friess, U., Gil Ojeda, M., Goutail, F., Graves, R., Griesfeller, A., Grossmann, K., Hemerijckx, G., Hendrick, F., Herman, J., Hermans, C., Irie, H., Johnston, P. V., Kanaya, Y., Kreher, K., Leigh, R., Merlaud, A., Mount, G. H., Navarro, M., Oetjen, H., Pazmino, A., Perez-Camacho, M., Peters, E., Pinardi, G., Puentedura, O., Richter, A., Schönhardt, A., Shaiganfar, R., Spinei, E., Strong, K., Takashima, H., Vlemmix, T., Vrekoussis, M., Wagner, T., Wittrock, F., Yela, M., Yilmaz, S., Boersma, F., Hains, J., Kroon, M., Piters, A., and Kim, Y. J.: Intercomparison of slant column measurements of $\mathrm{NO}_{2}$ and $\mathrm{O}_{4}$ by MAX-DOAS and zenith-sky UV and visible spectrometers, Atmos. Meas. Tech., 3, 1629-1646, doi:10.5194/amt-3-1629-2010, 2010.

Rothman, L. S., Barbe, A., Benner, D. C., Brown, L. R., Camy-Peyret, C., Carleer, M. R., Chance, K., Clerbaux, C., Dana, V., Devi, V. M., Fayt, A., Flaud, J. M., Gamache, R. R., Goldman, A., Jacquemart, D., Jucks, K. W., Lafferty, W. J., Mandin, J. Y., Massie, S. T., Nemtchinov, V., Newnham, D. A., Perrin, A., Rinsland, C. P., Schroeder, J., Smith, K. M., Smith, M. A. H., Tang, K., Toth, R. A., Vander Auwera, J., Varanasi, P., and Yoshino, K.: The HITRAN molecular spectroscopic database: edition of 2000 including updates through 2001, J. Quant. Spectrosc. Ra., 82, 5-44, 2003.

Rozanov, V. V. and Vountas, M.: Radiative transfer equation accounting for rotational Raman scattering and its solution by the discrete-ordinates method, J. Quant. Spectrosc. Ra., 133, 603618, 2014.

Rozanov, V. V., Rozanov, A. V., Kokhanovsky, A. A., and Burrows, J. P.: Radiative transfer through terrestrial atmosphere and ocean: Software package SCIATRAN, J. Quant. Spectrosc. Ra., 133, 13-71, 2014.

Schönhardt, A., Richter, A., Wittrock, F., Kirk, H., Oetjen, H., Roscoe, H. K., and Burrows, J. P.: Observations of iodine monoxide columns from satellite, Atmos. Chem. Phys., 8, 637-653, doi:10.5194/acp-8-637-2008, 2008.

Schönhardt, A., Altube, P., Gerilowski, K., Krautwurst, S., Hartmann, J., Meier, A. C., Richter, A., and Burrows, J. P.: A wide field-of-view imaging DOAS instrument for continuous trace gas mapping from aircraft, Atmos. Meas. Tech. Discuss., 7, 35913644, doi:10.5194/amtd-7-3591-2014, 2014.

Vandaele, A. C., Hermans, C., Simon, P. C., Roozendael, M. V., Guilmot, J. M., Carleer, M., and Colin, R.: Fourier transform measurement of $\mathrm{NO}_{2}$ absorption cross-section in the visible range at room temperature, J. Atmos. Chem., 25, 289-305, 1996.

Vandaele, A. C., Fayt, C., Hendrick, F., Hermans, C., Humbled, F., Van Roozendael, M., Gil, M., Navarro, M., Puentedura, O., Yela, M., Braathen, G., Stebel, K., Tornkvist, K., Johnston, P., Kreher, K., Goutail, F., Mieville, A., Pommereau, J. P., Khaikine, S., Richter, A., Oetjen, H., Wittrock, F., Bugarski, S., Friess, U., Pfeilsticker, K., Sinreich, R., Wagner, T., Corlett, G., and Leigh, R.: An intercomparison campaign of groundbased UV-visible measurements of $\mathrm{NO}_{2}, \mathrm{BrO}$, and OClO slant columns: methods of analysis and results for $\mathrm{NO}_{2}$, J. Geophys. Res.-Atmos., 110, D08305, doi:10.1029/2004jd005423, 2005.

Vasilkov, A. P., Joiner, J., Gleason, J., and Bhartia, P. K.: Ocean Raman scattering in satellite backscatter UV measurements, Geophys. Res. Lett., 29, 1837, doi:10.1029/2002GL014955, 2002. 
Vountas, M., Rozanov, V. V., and Burrows, J. P.: Ring effect: impact of rotational Raman scattering on radiative transfer in Earth's atmosphere, J. Quant. Spectrosc. Ra., 60, 943-961, 1998.

Vountas, M., Richter, A., Wittrock, F., and Burrows, J. P.: Inelastic scattering in ocean water and its impact on trace gas retrievals from satellite data, Atmos. Chem. Phys., 3, 1365-1375, doi:10.5194/acp-3-1365-2003, 2003.

Vountas, M., Dinter, T., Bracher, A., Burrows, J. P., and Sierk, B.: Spectral studies of ocean water with space-borne sensor SCIAMACHY using Differential Optical Absorption Spectroscopy (DOAS), Ocean Sci., 3, 429-440, doi:10.5194/os-3-429-2007, 2007.

Walrafen, G. E.: Raman spectral studies of effects of temperature on water structure, J. Chem. Phys., 47, 114-126, doi:10.1063/1.1711834, 1967.
Wittrock, F., Oetjen, H., Richter, A., Fietkau, S., Medeke, T., Rozanov, A., and Burrows, J. P.: MAX-DOAS measurements of atmospheric trace gases in Ny-Ålesund - Radiative transfer studies and their application, Atmos. Chem. Phys., 4, 955-966, doi:10.5194/acp-4-955-2004, 2004.

Wittrock, F., Richter, A., Oetjen, H., Burrows, J. P., Kanakidou, M., Myriokefalitakis, S., Volkamer, R., Beirle, S., Platt, U., and Wagner, T.: Simultaneous global observations of glyoxal and formaldehyde from space, Geophys. Res. Lett., 33, L16804, doi:10.1029/2006g1026310, 2006.

$\mathrm{Xu}, \mathrm{X}$. and Kattawar, G. W.: Filling in of Fraunhofer lines in the ocean by Brillouin-scattering, Appl. Optics, 33, 4835-4840, doi:10.1364/AO.33.004835, 1994. 